\title{
Modeling sugarcane yield with a process-based model from site to continental scale: uncertainties arising from model structure and parameter values
}

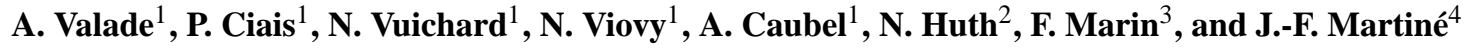 \\ ${ }^{1}$ LSCE, CEA-CNRS, Gif-sur-Yvette, 91191, France \\ ${ }^{2}$ CSIRO. Ecosystem Sciences, P.O. Box 102, Toowoomba, Qld, 4350, Australia \\ ${ }^{3}$ EMBRAPA Informatica Agropecuria, Barão Geraldo, 13083-886 Campinas SP, Brazil \\ ${ }^{4}$ CIRAD, UR SCA, Saint-Denis, La Réunion, 97408, France
}

Correspondence to: A. Valade (aude.valade@ipsl.jussieu.fr)

Received: 30 December 2013 - Published in Geosci. Model Dev. Discuss.: 31 January 2014

Revised: 22 May 2014 - Accepted: 26 May 2014 - Published: 30 June 2014

\begin{abstract}
Agro-land surface models (agro-LSM) have been developed from the integration of specific crop processes into large-scale generic land surface models that allow calculating the spatial distribution and variability of energy, water and carbon fluxes within the soil-vegetation-atmosphere continuum. When developing agro-LSM models, particular attention must be given to the effects of crop phenology and management on the turbulent fluxes exchanged with the atmosphere, and the underlying water and carbon pools. A part of the uncertainty of agro-LSM models is related to their usually large number of parameters. In this study, we quantify the parameter-values uncertainty in the simulation of sugarcane biomass production with the agro-LSM ORCHIDEESTICS, using a multi-regional approach with data from sites in Australia, La Réunion and Brazil. In ORCHIDEE-STICS, two models are chained: STICS, an agronomy model that calculates phenology and management, and ORCHIDEE, a land surface model that calculates biomass and other ecosystem variables forced by STICS phenology. First, the parameters that dominate the uncertainty of simulated biomass at harvest date are determined through a screening of 67 different parameters of both STICS and ORCHIDEE on a multisite basis. Secondly, the uncertainty of harvested biomass attributable to those most sensitive parameters is quantified and specifically attributed to either STICS (phenology, management) or to ORCHIDEE (other ecosystem variables including biomass) through distinct Monte Carlo runs. The uncertainty on parameter values is constrained using observations by calibrating the model independently at seven sites.
\end{abstract}

In a third step, a sensitivity analysis is carried out by varying the most sensitive parameters to investigate their effects at continental scale. A Monte Carlo sampling method associated with the calculation of partial ranked correlation coefficients is used to quantify the sensitivity of harvested biomass to input parameters on a continental scale across the large regions of intensive sugarcane cultivation in Australia and Brazil. The ten parameters driving most of the uncertainty in the ORCHIDEE-STICS modeled biomass at the 7 sites are identified by the screening procedure. We found that the 10 most sensitive parameters control phenology (maximum rate of increase of LAI) and root uptake of water and nitrogen (root profile and root growth rate, nitrogen stress threshold) in STICS, and photosynthesis (optimal temperature of photosynthesis, optimal carboxylation rate), radiation interception (extinction coefficient), and transpiration and respiration (stomatal conductance, growth and maintenance respiration coefficients) in ORCHIDEE. We find that the optimal carboxylation rate and photosynthesis temperature parameters contribute most to the uncertainty in harvested biomass simulations at site scale. The spatial variation of the ranked correlation between input parameters and modeled biomass at harvest is well explained by rain and temperature drivers, suggesting different climate-mediated sensitivities of modeled sugarcane yield to the model parameters, for Australia and Brazil. This study reveals the spatial and temporal patterns of uncertainty variability for a highly parameterized agro-LSM and calls for more systematic uncertainty analyses of such models. 


\section{Introduction}

In recent years, many governments have set targets in terms of biofuels consumption for transportation fuel (Sorda et al., 2010), resulting in a large increase in bioenergy cropping area around the world. Concerns about energy shortage, policy to reduce $\mathrm{CO}_{2}$ emissions, and the search for new income for farmers can explain why energy policies have considered biofuels as a serious alternative to fossil fuel in many countries (Demirbas, 2008). Yet, the claimed benefits of biofuels for fossil fuel substitution have been questioned in terms of their net effect on atmospheric $\mathrm{CO}_{2}$ and climate, and even of their economic return (Doornbosch and Steenblik, 2008; Naylor et al., 2007). In particular, the conditions of biofuel cultivation, such as the type of crop, practice, previous land use, and local climate, have emerged as key factors that determine the effectiveness of their carbon emissions reduction (Fargione et al., 2008; Hill et al., 2006; Searchinger et al., 2008). At the heart of biofuel cultivation is ethanol that represents today $74 \%$ of the energy content of the world production of liquid biofuels (Howarth et al., 2008) and whose production is expected to double between 2011 and 2021 (OECD, 2012), hence the urgency to better quantify and understand regional potentials of bioethanol crops. Based on recent life cycle analysis studies (de Vries et al., 2010; Schubert, 2006; von Blottnitz and Curran, 2007), ethanol from sugarcane is the most competitive in terms of energy use and net carbon balance, and the energy use projections from the International Energy Agency foresee that by 2050, sugarcane is the only first generation biofuel that that will keep expanding (IEA, 2011).

The impact of sugarcane expansion on climate and carbon balance is under scrutiny with different approaches. Satellite observation data have been used to study biophysical effects of sugarcane expansion on local temperature in the Brazilian Cerrado (Loarie et al., 2011). Surveys for agricultural and industrial performances from sugarcane mills have allowed Macedo et al. (2008) to establish the carbon balance of sugarcane ethanol production in the center-south of Brazil. Georgescu et al. (2013) simulate the hydroclimatic impacts of sugarcane expansion by forcing sugarcane land cover characteristics into a regional climate model. All approaches provide useful information on impacts and potentials but are impractical to apply outside of the regions and conditions (climate, management) where they have been conducted.

In parallel with empirical approaches, significant progress has been made towards mechanistic modeling of sugarcane yields using models. Crop models are generally used to simulate sugarcane production at site scale, with specific parameters (Cheeroo-Nayamuth et al., 2000). Land surface models (LSM) are rather used to estimate the spatial distribution of crop productivity under different soil and climatic conditions, over a region or even over the globe, but with a simpler and generic description of sugarcane plants (Black et al., 2012; Cuadra et al., 2012; Lapola et al., 2009). AgroLSM models stand at the interface between plot-scale crop models and global LSMs. Yet, as highlighted by Surendran Nair et al. (2012), if the development of agro-LSM models for biofuels has been the subject of much interest recently, detailed parameterization, validation and uncertainty quantification are still very limited in regional and global applications, and efforts must be made in that direction. The importance of evaluating and communicating about global models uncertainty was as well emphasized within the framework of the model inter-comparison project AgMIP - providing insights for IPCC AR5 report - in which crop models uncertainty is identified as a key theme of interest that has only been nominally explored so far (Rosenzweig et al., 2013). ORCHIDEE-STICS (Gervois et al., 2004) is an agro-LSM model that has been developed from the coupling of the agronomical model STICS (Brisson et al., 1998) and the land surface model ORCHIDEE (Krinner et al., 2005) and that has been applied for studies from site to continent mainly for temperate crops in Europe (Gervois et al., 2008) and has been recently adapted to sugarcane simulation (Valade et al., 2013).

Four uncertainty sources affect the simulation of sugarcane biomass with ORCHIDEE-STICS: (1) input uncertainty on boundary conditions used for climate drivers and soil properties, (2) structure uncertainty related to model equations and parameterizations, (3) parameter value uncertainty, and (4) uncertainty associated with the measurements used for model evaluation or calibration. Here we focus on structure and parameter uncertainty and try to estimate how these two sources of uncertainties affect the simulations of sugarcane harvest biomass. We want to determine which parameters are responsible for most of the uncertainty in harvest biomass (screening analysis) and to what extent this is related to the model's structure (uncertainty analysis). In addition, we want to quantify this uncertainty and examine its temporal and spatial variability (sensitivity analysis).

In the following, we first present the sites and regions considered in this study (Sect. 2.1) and the main features of the ORCHIDEE-STICS model (Sect. 2.2). We then describe the screening algorithm used to sort the most important parameters (Sect. 2.3), and the uncertainty and the sensitivity analyses (Sects. 2.4 and 2.5). Then we discuss the results of the screening analysis in terms of the parameters identified by the screening as the most important for controlling harvested sugarcane biomass (Sect. 3.1). We describe the results for the measure of the uncertainty calculated for seven sites in Sects. 3.2 to 3.4 and present maps of the sensitivity of the model to its main parameters in Sect. 3.5. 


\section{Materials and methods}

In this study, we aim to quantify the uncertainty related to the parameter values of a chain of two process-based models (ORCHIDEE-STICS) to simulate sugarcane yield (biomass at harvest date). This is a difficult task because this model is a detailed and complex model that contains over 100 plant specific parameters within the primitive equations of phenology, energy and water balance, photosynthesis and allocation. We perform the uncertainty analysis in three steps, illustrated in Fig. 1 and consisting of screening, uncertainty and sensitivity analyses, all described in more details in Sect. 2. These three steps are sequential and complementary. The first step is a screening to sort the most important parameters controlling yield, and to reduce the dimension of the parameter space from a large number of parameters to few key parameters, allowing a moderate number of sensitivity simulations. The screening allows the restriction of the two further steps to a smaller parameter subset. The second step is an uncertainty analysis that considers all retained parameters together with their probability distributions, and determines the probability distribution for the output variable (biomass). The third step is a sensitivity analysis of the modeled spatial distribution of sugarcane yield to the model parameters for two large regions, in Brazil and Australia, at a spatial resolution of $0.7^{\circ}$. The sensitivity is established from the spatial distribution of ranked correlations between each parameter and yield in each grid point. Along the study steps, we address several problems inherent to uncertainty and sensitivity evaluation, such as the determination of the uncertainty on the input parameters and the spatial (regional) differences of the sensitivity of the model to its key parameters.

\subsection{Sites and study areas}

This study is based on sugarcane field trials in three regions (Fig. 2) where sugarcane is of economical importance, Brazil (1 site), Australia (4 sites), and La Réunion Island (2 sites). These sites, already used by Valade et al. (2013), span different climatic conditions and agricultural practices, as shown in Table 1, which makes them useful for our purpose to provide continental-scale sugarcane yield uncertainty estimates. More details about the four sites from Australia and La Réunion can be found respectively in Keating et al. (1999), Muchow et al. (1994), Robertson et al. (1996) and in Martiné (unpublished). The site from Brazil is described in Marin et al. (2011). The sensitivity analysis of the yield spatial distribution to the model parameters is carried out for two continental-scale areas where sugarcane is cultivated at large scale. In Brazil, we consider the region encompassing partly the São Paulo and Mato Grosso states, and in Australia the sugarcane cultivation belt of the northeastern coast (Fig. 2).

\subsection{Model and parameters considered}

We use the agro-land surface model ORCHIDEE-STICS (Gervois et al., 2004) in a version that was already calibrated for sugarcane for leaf area index at the same sites as used here (Valade et al., 2013). This model chains the crop model STICS with sugarcane specific phenology and management with the generic process-based land surface model ORCHIDEE that can be applied either at a site, or on a grid for regional runs.

STICS (Brisson et al., 1998) is an agronomical model designed for site-scale operational applications, which describes in detail the soil and crop processes associated with specific crop varieties and with management practices, such as aboveground biomass, and biomass nitrogen content, water and nitrogen content in the soil, yield, and root density. Yet, STICS is a generic crop model, because from a set of common equations it can describe a large number of crop species through specific parameterizations. Similarly, specific vectors of parameters define crop cultivars. STICS has been validated for a variety of cropping situations (Brisson et al., 2003)

ORCHIDEE (Krinner et al., 2005) is a land surface model developed for global applications, standing now as the land surface model of the IPSL Earth System Model. It has been developed from the association of a surface energy and water balance scheme (SECHIBA) with a biogeochemistry module (STOMATE) and as such simulates the short timescale exchanges of water and energy between the land surface and the atmosphere, as well as the processes of the carbon cycle including photosynthesis, respiration, carbon allocation, and soil decomposition. The vegetation is represented in ORCHIDEE with the plant functional type (PFT) concept by grouping species into a few categories based on the similarities of their traits and resulting in an average plant. For example, sugarcane would fall in the generic "C4 crop" PFT in the standard version of ORCHIDEE, and this uncalibrated version of model fails to reproduce site-level phenology, as shown by Valade et al. (2013).

The chaining of STICS with ORCHIDEE was performed to improve the ability of ORCHIDEE to simulate specific crops, for which the PFT concept was not appropriate, as it lacks representation of crop phenology and crop management practices (Gervois et al., 2004). In the chain-like structure (Fig. 3), STICS calculates phenology, water and nitrogen requirements, and passes the key variables of leaf area index (LAI), root profile and nitrogen stress as well as the input data concerning irrigation requirements to ORCHIDEE that uses them to calculate carbon assimilation and allocation, water balance, and energy-related variables. The oneway coupling between the two models can generate some inconsistencies, such as the soil status that is different between ORCHIDEE and STICS. This type of inconsistency, inherent to the structure of the model, is considered as part of the structural uncertainty and is not covered in this study. 


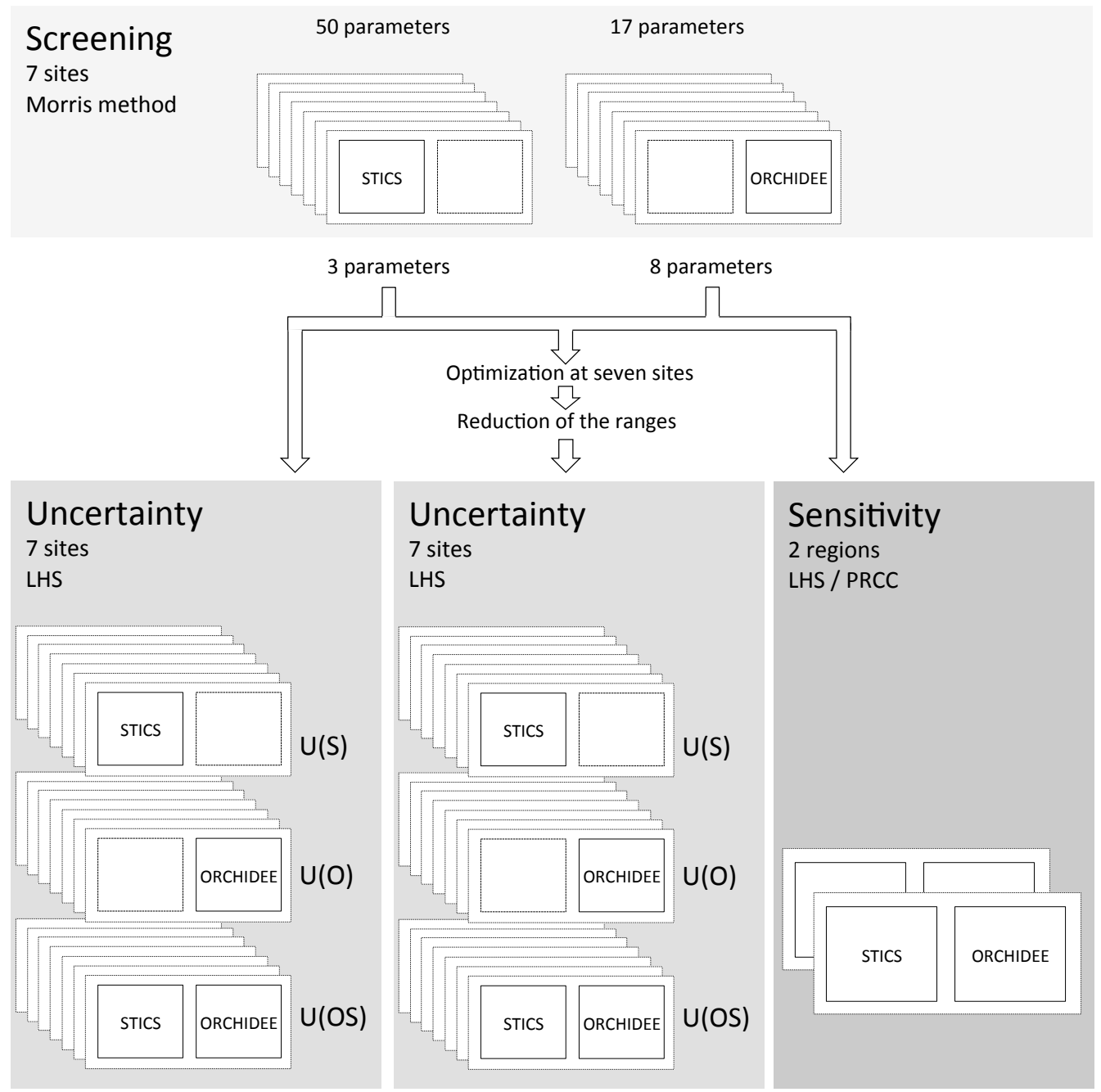

Figure 1. Flowchart of the analysis carried out in this study. The first step is the separate screening for seven sites of the STICS and ORCHIDEE parameters. The selection of parameters obtained from the screening are then used for two uncertainty analysis, one with the same parameter ranges of variation as for the screening, the other with parameter ranges of variation constrained by the optimization of the model at seven sites. Each uncertainty analysis is decomposed in three parts, one including only ORCHIDEE parameters, one including only STICS parameters and one including parameters from both ORCHIDEE and STICS. Finally a sensitivity analysis is carried out for two small regions in Australia in Brazil for all parameters together.

Table 1. Description of climate and management for the sites used in this study in Australia (Ayr, Ingham, Grafton), Brazil (Piracicaba) and La Réunion (Colimaçons, Tirano).

\begin{tabular}{lllllll}
\hline & \multicolumn{2}{c}{$\begin{array}{c}\text { Planting and } \\
\text { harvest dates }\end{array}$} & $\begin{array}{l}\text { Mean annual } \\
\text { precipitation }\end{array}$ & $\begin{array}{l}\text { Average } \\
\text { temperature }\end{array}$ & Irrigation & $\begin{array}{l}\text { Fertilization } \\
\text { irrigation }\end{array}$ \\
\hline Ayr & $4 / 19 / 1991$ & $8 / 13 / 1992$ & 964 & 23.4 & irrigated & no \\
Ayr & $4 / 22 / 1992$ & $8 / 13 / 1993$ & 560 & 23.6 & irrigated & yes \\
Grafton & $9 / 28 / 1994$ & $9 / 19 / 1995$ & 768 & 19.6 & irrigated & yes \\
Ingham & $7 / 23 / 1992$ & $10 / 21 / 1993$ & 1294 & 24.2 & irrigated & yes \\
Piracicaba & $10 / 29 / 2004$ & $9 / 26 / 2005$ & 1230 & 21.6 & irrigated & \\
Colimaçons & $8 / 3 / 1994$ & $12 / 1 / 1995$ & 989.5 & 19 & rainfed & yes \\
Tirano & $11 / 26 / 1998$ & $11 / 26 / 1999$ & 813 & 22.34 & irrigated & yes \\
\hline
\end{tabular}




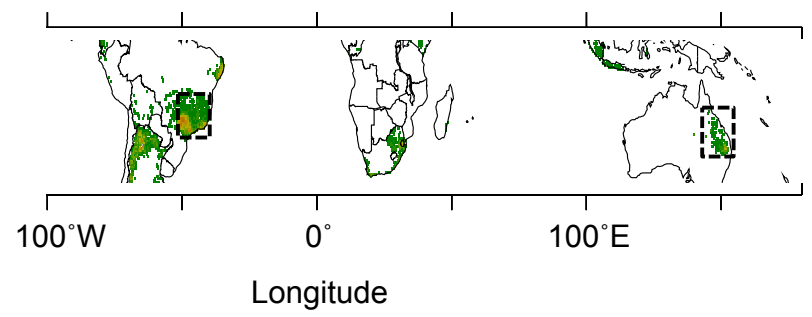

Figure 2. Spatial distribution of the regions (dashed rectangles) used in this study overlaid on a map of the distribution of sugarcane growing areas indicated in green.

However, this particular one-way structure will have a consequence in the uncertainty that we are analyzing in this study.

ORCHIDEE and STICS each have a large number of parameters involved at every step of a simulation over the course of a growing season. The values of these parameters - often empirically prescribed - are not easy to measure or are not measurable at all, calling in many cases for expert judgment to set their values, when it is impractical to find reference values. The uncertainty of these parameters is propagated onto the output variables of ORCHIDEE STICS and has impacts whose strength depends on the structure of both STICS and ORCHIDEE. Because of the chain-type structure of ORCHIDEE-STICS (Fig. 3), the parameters from STICS that control LAI and nitrogen stress are expected to have a weaker and more indirect effect on downstream variables, such as biomass compared with parameters from ORCHIDEE that directly control carbon assimilation processes, and the development of biomass to produce yield at the date of harvest.

\subsection{Parameter screening}

In this section, we describe the screening step that allows us to select the most influential parameters upon which the model uncertainty is investigated. An initial set of 17 parameters from ORCHIDEE and 50 parameters from STICS is considered for the screening, according to their influence on the simulation of biomass production, based on expert knowledge and literature as listed in Table 2. The screening analysis procedure is the same as described in Valade et al. (2013). It is based upon the method of Morris (Campolongo et al., 2007; Morris, 1991; Pujol, 2009) often used to explore the parameters space for complex models with a large number of parameters. Like all screening methods, the Morris method gives qualitative information on the sensitivity of the output variables to the parameters, since it only discriminates parameters based on their importance, but does not provide information on the relative difference of importance (Cariboni et al., 2007). Its aim is to reduce the dimensionality of the problem for further use of quantitative, computationally heavier methods (Saltelli et al., 2004).
The advantage of the Morris method is that it is computationally efficient and easy to implement and interpret. It is based on a one-at-a-time approach, in which only one parameter is changed between two runs, allowing for the calculation of a local partial derivative of the output variable with respect to the input parameter, called an elementary effect. The Morris method is considered to be a "global" screening method, because the algorithm is repeated several times to calculate the elementary effects of each parameter in several locations of the parameters space, so that the average and standard deviation of all elementary effects associated with each parameter are representative of the behavior of this parameter in its whole range of variation. The results of the Morris screening algorithm can be represented by a 2-D plot of standard deviation versus mean value of the elementary effects on the output variable (here harvested biomass) of each parameter. A parameter with a high mean elementary effect (called $\mu$, or $\mu *$ for mean of absolute values) is interpreted as a parameter with high influence on the output harvested biomass variable. A parameter with a high standard deviation of its elementary effects $(\sigma)$ is interpreted as inducing non-linearities in the model output, and/or as having interactions with other parameters.

Here, we apply the Morris method as implemented in the R "sensitivity" package (Pujol et al., 2013) using site-scale simulations of ORCHIDEE STICS across the seven field trial sites listed in Table 1. For each site, we identify the most influential parameters for the output variable harvested biomass. The parameters identified as important at least at two sites are selected for the rest of the study.

\subsection{Uncertainty analysis (UA)}

The goal of the UA is to quantify the overall uncertainty in the harvested biomass output variable that results from uncertain input parameter values. Firstly, based on the a priori probability of each parameter's value, a probability density function is assigned to each parameter in order to generate sample parameter sets according to the Latin Hypercube Sampling (LHS) method. Secondly, an ensemble of model runs is performed using those samples. Thirdly, the uncertainty on the output variables is obtained from the statistical properties of the distribution of simulated harvested biomass from the ensemble runs by defining the uncertainty as one standard deviation of the distribution.

The first step is thus to generate parameter samples constrained with prior parameter ranges and statistical distributions that are then used as inputs for ensemble simulations.

The parameters considered for the uncertainty (UA) for both STICS and ORCHIDEE are those selected by the screening analysis, allowing a reduction in the parameters space hypercube dimensionality and therefore in the required computing resources. Starting from the initial set of 17 and 50 parameters, respectively, for the screening of ORCHIDEE and STICS parameters, the Morris algorithm result 
Table 2. List of parameters from STICS and ORCHIDEE included in each step of the analysis with their ranges of variation. Parameters in bold indicate parameters identified by the screening analysis as the most important for uncertainty propagation.

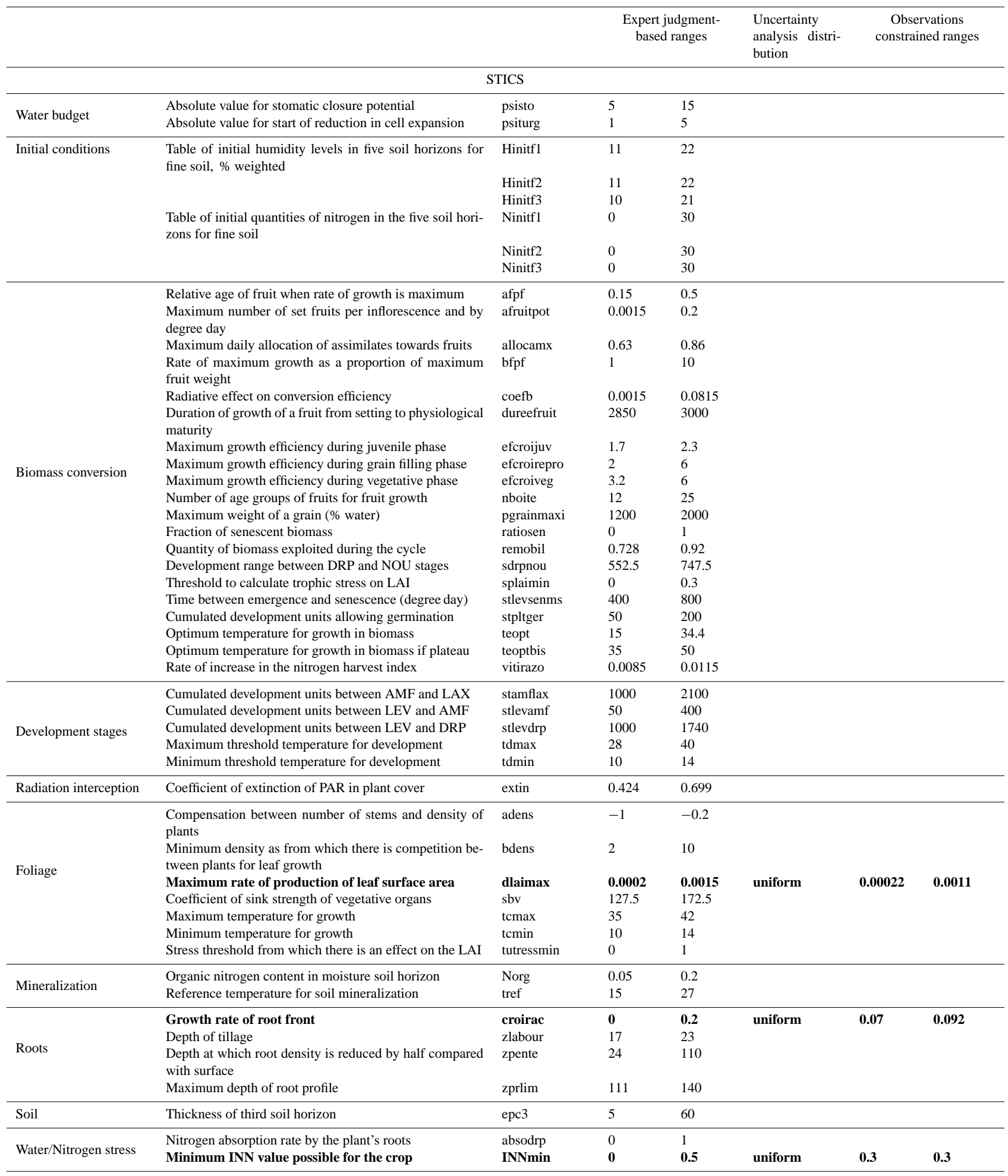


Table 2. Continued.

\begin{tabular}{|c|c|c|c|c|c|c|c|}
\hline & & & \multicolumn{2}{|c|}{$\begin{array}{l}\text { Expert judgment- } \\
\text { based ranges }\end{array}$} & \multirow{2}{*}{$\begin{array}{l}\text { Uncertainty } \\
\text { analysis distri- } \\
\text { bution }\end{array}$} & \multicolumn{2}{|c|}{$\begin{array}{l}\text { Observations } \\
\text { constrained ranges }\end{array}$} \\
\hline \multicolumn{7}{|c|}{ ORCHIDEE } & \\
\hline \multirow{7}{*}{ Allocation } & & f_fruit & 0.05 & 0.5 & & & \\
\hline & Maximum LAI per PFT & lai_max & 3 & 9 & & & \\
\hline & Average critical age for leaves & leaf_age_crit & 30 & 200 & & & \\
\hline & Upper bounds for leaf allocation & max_lto_lsr & 0.25 & 0.5 & & & \\
\hline & Lower bounds for leaf allocation & min_lto_lsr & 0.05 & 0.24 & & & \\
\hline & Root allocation & R0 & 0.05 & 0.5 & & & \\
\hline & Sapwood allocation & So & 0.05 & 0.5 & & & \\
\hline \multirow{6}{*}{ Photosynthesis } & Extinction coefficient & ext_coef & 0.5 & 0.9 & uniform & 0.5 & 0.72 \\
\hline & $\begin{array}{l}\text { Slope of relationship between assimilation and stom- } \\
\text { atal conductance }\end{array}$ & gsslope & 7 & 11 & beta $(2,2)$ & 7.7 & 9.5 \\
\hline & Temperature at which photosynthesis is maximal & tphoto_max & 30 & 45 & & & \\
\hline & Temperature at which photosynthesis is minimal & tphoto_min_c & 12 & 19 & uniform & 12 & 16.7 \\
\hline & Temperature at which photosynthesis is optimal & tphoto_opt & 24 & 36 & uniform & 24 & 36 \\
\hline & Maximum carboxylation rate & vcmax_opt & 40 & 100 & beta $(2,2)$ & 64 & 81.3 \\
\hline \multirow{2}{*}{ Respiration } & Fraction of biomass available for growth respiration & frac_growthresp & 0.2 & 0.5 & beta $(2,2)$ & 0.23 & 0.3 \\
\hline & $\begin{array}{l}\text { Slope of the relationship between temperature and } \\
\text { maintenance respiration }\end{array}$ & maint_resp_slope1 & 0.08 & 0.16 & beta $(2,2)$ & 0.11 & 0.12 \\
\hline Water budget & $\begin{array}{l}\text { Root profile to determine soil moisture content avail- } \\
\text { able to plants }\end{array}$ & humcste & 0.8 & 7.2 & uniform & 3.2 & 4.1 \\
\hline
\end{tabular}

(see Sect. 3.1) allows us to reduce the parameter numbers to 8 and 3 parameters for ORCHIDEE and STICS.

For the UA, we use Monte Carlo methods, which are computationally less expensive than variance-based approaches (Marino et al., 2008), making them a frequent choice in environmental sciences (Poulter et al., 2010; Verbeeck et al., 2006; Zaehle et al., 2005). The Monte Carlo sampling scheme used here is the stratified LHS, which is an efficient scheme for generation of multivariate samples of statistical distributions (McKay et al., 1979). In LHS, the range of each of the $k$ parameters $X_{1}, X_{2}, \ldots X_{k}$ included in the study is divided into $N$ intervals of equal probability. One value is randomly selected from each interval. The $N$ values obtained for the $X_{1}$ parameter are then paired at random, without replacement, with the $N$ values obtained for the $X_{2}$ parameter, then to the $N$ values obtained for the $X_{3}$ parameter and so on until the $k$ th parameter. The procedure results in $N$ sets of $k$ parameters, or samples, that can be used for input to the model. In this study, from the 11 parameters identified by the screening, the $N$ value is set to 250 , resulting in 250 simulations for exploring the uncertainty around modeled biomass for each site.

In order to get insights on the part of the uncertainty attributable to each of the two models chained together, STICS and ORCHIDEE (Fig. 1), first, only the uncertainty coming from ORCHIDEE parameters is evaluated (Fig. 1), secondly, only the uncertainty propagated from STICS parameters (Fig. 1), and last, uncertainties propagated from both ORCHIDEE and STICS parameters are considered together through the chained model ORCHIDEE-STICS.
An important difficulty in the utilization of samplingbased UA methods is the lack of literature about a priori probability distribution of most parameters, given the dependency of output upon a priori assigned values (Marino et al., 2008). If most studies rely on a thorough literature search and expert judgment (Medlyn et al., 2005; Verbeeck et al., 2006; Wang et al., 2005), this approach might result in an overestimation of the model output uncertainty due to combinations of extreme parameters values that are not realistic and therefore excessively decrease the estimated reliability of the models. Some studies have addressed this issue by trying to rationalize the parameter ranges through benchmarking outputs (removing parameter sets resulting in values for output variables outside of a given benchmark range) or by prescribing hypothesized correlations between parameters (Poulter et al., 2010; Zaehle et al., 2005). Here, after a first estimation of uncertainty based on expert opinion for the a priori parameter range (overestimation of uncertainty), we propose a second approach to overcome the scarcity of information about parameter reference distributions by reducing the parameters a priori range based on site-optimized values, thus providing narrower and more realistic a priori ranges that are constrained by observations (likely underestimation of uncertainty).

For the first a priori estimation of parameter range, ranges and distributions are assigned to parameters based on expert knowledge and previous parameterization studies (Kuppel et al., 2012) and centered on their a priori values. The a priori ranges prescribed using this approach are considered as overestimations of the likely ranges for parameters' values for sugarcane because they are adapted from studies in which parameters' ranges were assigned for plant functional 


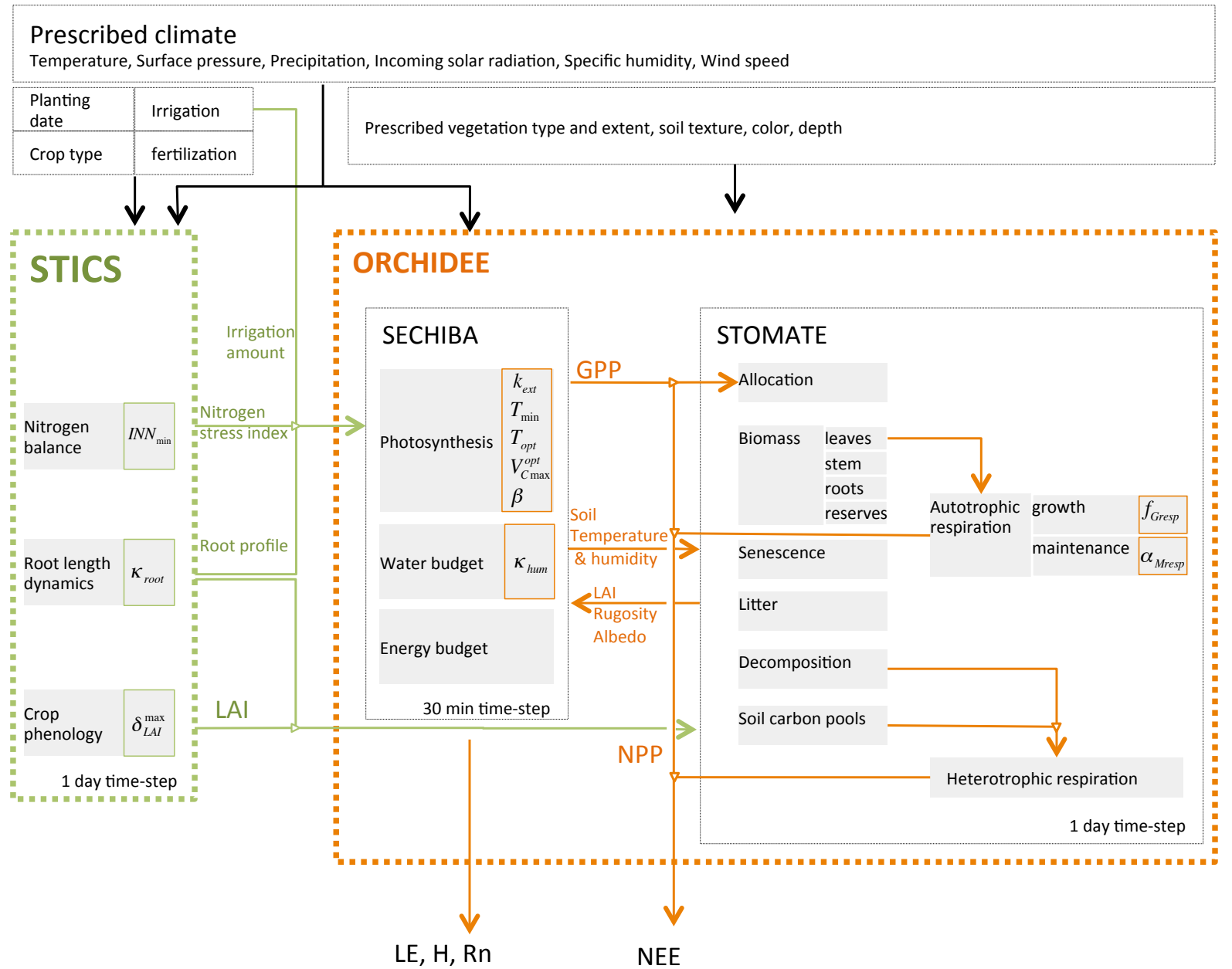

Figure 3. Structure of the ORCHIDEE-STICS chain model. STICS calculates the crop phenology, water and nitrogen requirements and passes LAI, root profile, irrigation and nitrogen nutrition index to ORCHIDEE. ORCHIDEE consists in the coupling of two module. SECHIBA simulates the photosynthesis process, water and energy budgets; STOMATE is a carbon module and calculates carbon fluxes and to the atmosphere (respiration) and carbon accumulation in the carbon pools (biomass compartments, litter, soil).

types instead of a single crop, as is the case here, and sometimes used for optimization studies, therefore requiring wide enough ranges within the model's domain of applicability (Groenendijk et al., 2011; Kuppel et al., 2012). By using overestimated ranges for input parameters, we estimate an upper bound for the value of the uncertainty on output variables.

The second (site-constrained) a priori estimation is a refinement of the uncertainty estimation based on the idea that the "real" probability distribution of the parameters can be approached by the distribution of optimal parameters over all the possible case studies (sites, weather, management). It is of course not possible to determine the model's optimal parameters for an infinite number of eco-climatic and land-management conditions, but a sample of representative case studies can provide a rough estimate of the parameters plausible range. Building on this hypothesis, the model is calibrated independently at seven sites using an iterative method, seeking to constrain the uncertainty analysis with observation-based parameter ranges. For this, we performed a Bayesian calibration of the model parameters, using a standard variational method based on the iterative minimization of a cost function that measures both the model data misfit as well as the parameters' deviations from prior knowledge. The iterative scheme is described in Tarantola (1987) with the hypothesis of Gaussian error on the observations and the parameters. At each site, parameter values are varied iteratively until the best match between simulation and observation is found. More details on the calibration results can be found in the Supporting Information. We are aware that the optimization of the parameters at seven sites only to obtain a representative a priori range of the parameters distributions likely results in an optimistic estimate of this range even though the sites chosen cover different climatic, edaphic and management conditions, making them well suited for applying our method. This observations-constrained range is 
highly dependent on growing conditions. When the model is applied to the context of climate change, these ranges may then be out of their domain of significance and the first wider estimate of prior parameters distribution, based on literature, must be preferred.

For both a priori parameter range estimations (expert judgment vs. site constrained), when no parameter value appears to be more likely than another, a uniform a priori uncertainty distribution is prescribed. When there is some level of confidence that the a priori value is more likely, we use a beta distribution. This type of distribution is often used for uncertainty analyses, because of its adjustable shape (parameterized equation) and advantage of having bounded tails (Monod et al., 2006; Wyss and Jorgensen, 1998). The successive analysis of both techniques provides an improvement in the estimation of the uncertainty from the first (expert-judgment based, likely too pessimistic) to the second (observation-based, perhaps too optimistic) approach.

\subsection{Spatial sensitivity analysis (SA)}

The first step in the sensitivity analysis also consists in generating parameter samples. The same parameters are considered for the SA as for the UA (Sect. 2.4), that is, the 11 parameters (8 parameters from ORCHIDEE and 3 parameters from STICS) selected by the screening analysis.

As opposed to the UA where all parameters are considered together for their effect on the distribution of the harvested biomass output variable, the goal of the sensitivity analysis is to rank the influence of parameters based on their impact on the biomass and its spatial distribution obtained in the continental-scale $0.7^{\circ}$ runs. The partial correlation coefficient (PCC) measures the correlation between an output variable and a parameter after the correlation with other parameters has been eliminated (Marino et al., 2008). However, for monotonic but non-linear relationships, these measures perform poorly and a rank transformation needs to be applied to the data first to linearize the relationship. The correlation calculated between the rank-transformed data is then called partial rank correlation coefficients (PRCC). PRCC has been found to be an efficient indicator for the influence of parameters, because it is a measure of the sensitivity of the output to parameters (Saltelli and Marivoet, 1990). The larger the PRCC, the more important the parameter is with respect to the output variable. Here, the relationship between modeled biomass on a grid, and parameters is diagnosed through the calculation of the partial ranked correlation coefficients (PRCC) on each grid point between the output and parameter, assuming a monotonic behavior of the model.

The SA is implemented from the results of the $0.7^{\circ}$ simulations over Brazil and Australia (see Fig. 1 and Sect. 3.5). In this regional sensitivity analysis, ORCHIDEE-STICS is run for each region on a grid of 20 by 15 grid points and 13 by 20 grid points, respectively, driven by gridded climate forcing fields from the reanalysis products ERA-Interim (Dee et al., 2011), with varying parameter values from a sampling where only bounds and no distributions were assigned to the parameters. The management information (date of planting, date of harvest, fertilization, irrigation) and the soil properties (as described in Valade et al., 2013) are assumed to be uniform across each region and were defined as typical of each area. The a priori bounds used for the parameters in the SA correspond to the first version of the parameter ranges considered in the uncertainty analysis (i.e., derived from expert knowledge). As cited by Wang et al. (2005), for sensitivity analyses, Bouman (1994) advises using parameter ranges as broad as possible within the limits of the model validity domain. Once the parameters' a priori bounds have been set, ensemble runs are performed with all the parameter sets. From the distributions of input parameters and output variables obtained at each pixel, a spatial distribution of PRCC is obtained, which is interpreted in Sect. 3.5 in terms of regional differences of each parameter on modeled sugarcane yield.

The interest of carrying out such a regional sensitivity analysis is that it provides maps of the geographic patterns of the importance of each parameter, leading to a better comprehension of the mechanisms behind the parameter-related model sensitivity. These results can be very useful for planning purposes, for instance when quantifying the different factors controlling sugarcane yield and ethanol production over a large region under future climatic conditions as compared to present-day conditions.

\section{Results and discussion}

\subsection{Screening}

From the Morris screening method, we obtain for each parameter two indices $\mu *$ and $\sigma$, that measure the influence of each parameter and its degree of involvement in nonlinearities and interactions with other parameters, respectively. We first made sure that no parameter with a significant value for $\mu *$ was above the line $\sigma=2 \mu *$, which would imply that non-linearities and/or interactions would be so strong that the uncertainty propagation from the parameter to the model output could not be clearly established. None of our parameters selected for their significant values of $\mu *$ was above this line (Fig. S2 in the Supplement). From $\mu *$ and $\sigma$ values, we establish a ranking of the parameters by only considering parameters involved in limited interactions and/or non-linearities $(\sigma<2 \mu *)$ and then we rank the remaining parameters based on their $\mu *$ index, a larger $\mu *$ being interpreted as a more influential parameter. The Morris parameters ranks for ORCHIDEE and STICS are respectively shown in Fig. 5a and b, where each radar plot corresponds to one model. The axes refer to the parameters and the line colors to the sites. For STICS, for the sake of readability, not all of the initially selected 50 parameters are represented on the 


\begin{tabular}{|c|c|c|c|}
\hline \multicolumn{4}{|l|}{ STICS } \\
\hline $\begin{array}{l}\delta_{L A}^{\max }: \text { daily maximum increment } \\
\quad \text { of LAI }\left(\mathrm{m}^{2} \cdot \mathrm{plt}^{-1} \cdot \text { deg-day }^{-1}\right) \\
I N N_{\min }: \text { threshold for nitrogen } \\
\text { nutrition index (unitless) }\end{array}$ & 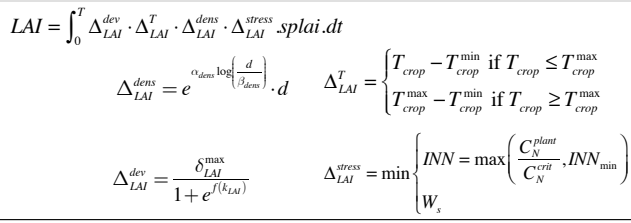 & 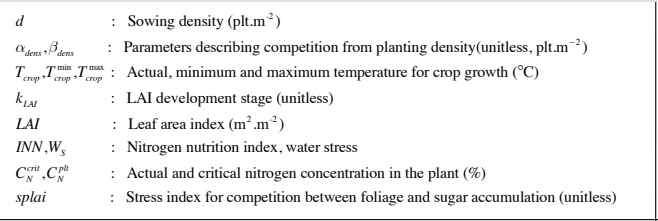 & $\begin{array}{l}\text { (Brisson et al., } \\
2009)\end{array}$ \\
\hline$\kappa_{\text {root }}:$ root growth rate & $z_{\text {tort }}^{\mathrm{etf}}=\int_{0}^{T} K_{\text {rat }} \cdot f_{\Delta r} \cdot p f z \cdot f_{\text {anax }} \cdot d t$ & 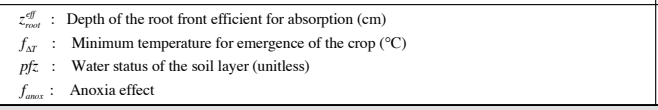 & $\begin{array}{l}\text { (Brisson et al., } \\
2009 \text { ) }\end{array}$ \\
\hline \multicolumn{4}{|l|}{ ORCHIDEE } \\
\hline$k_{e x t}:$ extinction coefficient (unitless) & light $=e^{-k_{\text {ex }} \cdot L A I}$ & light : Light fraction that goes through the vegetation & Saeki, 1953) \\
\hline $\begin{array}{l}T_{\min } / T_{o p t}: \text { Minimum / Optimal } \\
\text { photosynthesis temperatures }\left({ }^{\circ} \mathrm{C}\right)\end{array}$ & $\varepsilon_{\text {temp }}=f\left(T_{\text {air }}, T_{\min }, T_{o p t}\right)$ & $\varepsilon_{\text {temp }}:$ Limitation of photosynthesis capacity by temperature & $\begin{array}{l}\text { (Krinner et al., } \\
2005)\end{array}$ \\
\hline $\begin{array}{l}V_{c \max }^{o p t}: R \text { ate of carboxylation in } \\
\text { optimal conditions }\left(\mu \mathrm{mol} \cdot \mathrm{m}^{-2} \cdot \mathrm{s}^{-1}\right)\end{array}$ & $V_{C \max }=V_{C \max }^{o p t} \cdot \varepsilon_{\text {temp }} \cdot \varepsilon_{\text {water }} \cdot \varepsilon_{\text {leaf }}$ & 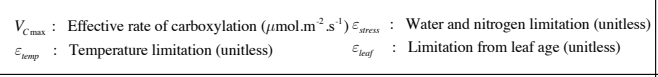 & $\begin{array}{l}\text { (Ishida et al., } \\
\text { 1999) }\end{array}$ \\
\hline$\beta:$ Ball-Berry slope (unitless) & $\mathrm{g}_{s}=\beta \frac{h_{r}}{C_{a}} A+g_{s}^{o f f i e t}$ & 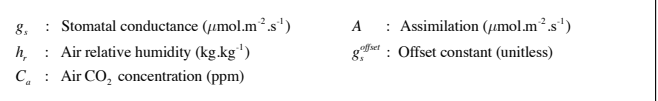 & $\begin{array}{l}\text { (Ball et al., } \\
\text { 1987) }\end{array}$ \\
\hline$\kappa_{\text {hum }}:$ Root profile description $\left(\mathrm{m}^{-1}\right)$ & 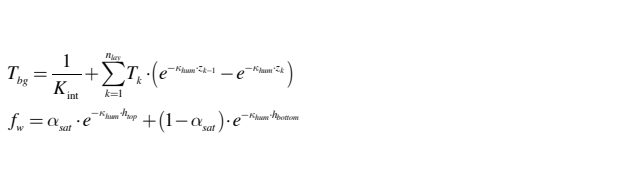 & 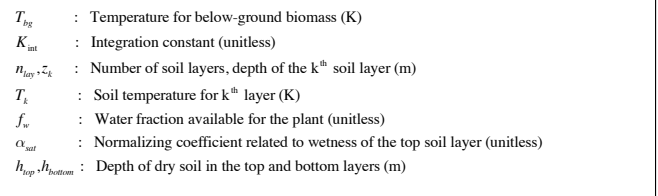 & $\begin{array}{l}\text { (Krinner et al., } \\
2005)\end{array}$ \\
\hline $\begin{array}{l}f_{\text {Gresp }}: \text { fraction of GPP lost as growth } \\
\text { respiration (dimensionless) }\end{array}$ & Gresp $=\frac{1}{\Delta t}\left(f_{\text {Gresp }} \cdot B_{\text {alloc }}\right)$ & $\begin{array}{l}\text { Gresp : } \text { Growth respiration }\left(\mathrm{gC} \cdot \mathrm{m}^{2} \cdot \mathrm{dt}^{-1}\right) \\
B_{\text {alloc }}: \text { : Allocatable biomass }\left(\mathrm{gC} \cdot \mathrm{m}^{2}\right)\end{array}$ & $\begin{array}{l}\text { (Ruimy et al., } \\
\text { 1996) }\end{array}$ \\
\hline $\begin{array}{l}\alpha_{\text {Mresp }}: \text { slope of the dependance on } \\
\text { temperature of maintenance } \\
\text { respiration coefficient }\left(\mathrm{K}^{-1}\right)\end{array}$ & $\begin{array}{l}c_{i}=\max \left\{\begin{array}{l}0 \\
c_{i}^{0}\left(1+\alpha_{\text {Mresp }} T_{i}\right)\end{array}\right. \\
\text { Mresp }=\frac{1}{\Delta t}\left(\sum_{\text {itleaf }} c_{i} \cdot B_{i}+c_{\text {leaf }} \cdot B_{\text {leaf }} \cdot \frac{0.3 \cdot L A I+1.4\left(1-e^{-k \cdot L A I}\right)}{L A I}\right)\end{array}$ & $\begin{array}{ll}c_{i} & : \text { Fraction of biomass lost as maintenance respiration for part } i \text { (unitless) } \\
c_{i}^{0} & : \text { Prescribed maintenance respiration coefficients at } 0 \text { Degree Celsius (unitless) } \\
T_{i} & : \text { Air (soil for belowground compartments) temperature }\left({ }^{\circ} \mathrm{C} \text { ) }\right. \\
\mathrm{M}_{\text {repp }} & : \text { Maintenance respiration }\left(\mathrm{gC}^{-2} \cdot \mathrm{m}^{-2} \mathrm{dt}^{-1}\right) \\
B_{i} & : \text { Biomass in compartment } \mathrm{i}\left(\mathrm{gC} \cdot \mathrm{m}^{-2}\right)\end{array}$ & $\begin{array}{l}\text { (Krinner et al., } \\
\text { 2005; Ruimy et } \\
\text { al., 1996) }\end{array}$ \\
\hline
\end{tabular}

Figure 4. Main parameters for simulation of sugarcane yield with ORCHIDEE-STICS with the equations in which they are involved.

radar plot but only those parameters that pertain to the 10 topranked parameters at least at one site. The maximum number of 10 parameters was fixed based on examination of Morris indices $\mu *$ and $\sigma$ at individual sites that only revealed 3 to 5 sensitive parameters each time. The positions and roles in the model of the parameters identified as most important are shown in Fig. 3. Figure 4 gives more details, with the main equations through which these parameters affect the output variables of STICS and of ORCHIDEE.

The three most influential parameters of STICS (Fig. 3a) reflect the way STICS and ORCHIDEE are chained (Fig. 3). Indeed, from the chained model structure, the indirect impact of STICS parameters on harvested biomass occurs through their effect on processes related to LAI, root growth and nitrogen stress, the only STICS variables passed to ORCHIDEE for calculating biomass. This chaining of the models through three variables is reflected in the identification of the three most important STICS parameters, which control the daily maximum rate of foliage production, $\delta_{\mathrm{LAI}}^{\max }$, the growth rate of the root front, $\kappa_{\text {root }}$, and the threshold of nitrogen nutrition index, $\mathrm{INN}_{\min } . \delta_{\mathrm{LAI}}^{\max }$ and $\mathrm{INN}_{\min }$ parameters are both involved in LAI calculation. Indeed, the LAI equation has four members describing four processes of the sugarcane foliage development. First, the LAI development $\left(\Delta_{\mathrm{LAI}}^{\mathrm{dev}}\right.$ in Fig. 4) describes the potential LAI increase through the scaling of the daily maximum rate of foliage production by a function of the development stage $\left(k_{\mathrm{LAI}}\right)$, and is logically directly controlled by the value of parameter $\delta_{\mathrm{LAI}}^{\max }$. The second member in the equation represents the temperature effect on LAI growth through the accumulation of degrees above a temperature threshold ( $T_{\min }$ in Fig. 3). The last two members of the equation represent processes that can limit LAI development, competition for light between plants due to planting

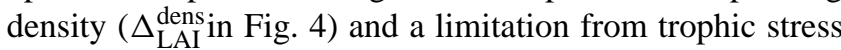
emerging from competition between plant components for nitrogen based on calculation of a nitrogen nutrition index limited by parameter $\mathrm{INN}_{\min }$. The root growth rate $\kappa_{\text {root }}$ has a less direct impact on LAI since it intervenes in the calculation of the root front depth, which then impacts the availability of nitrogen and water and therefore the stress status of the crop (impact on $C_{\mathrm{N}}^{\text {plant }}$ and $W_{\mathrm{s}}$ in Fig. 4).

The eight most influential parameters that control harvested biomass in ORCHIDEE, are identical for all sites except at the Colimaçons site (where only seven parameters are 
(a) STICS parameters

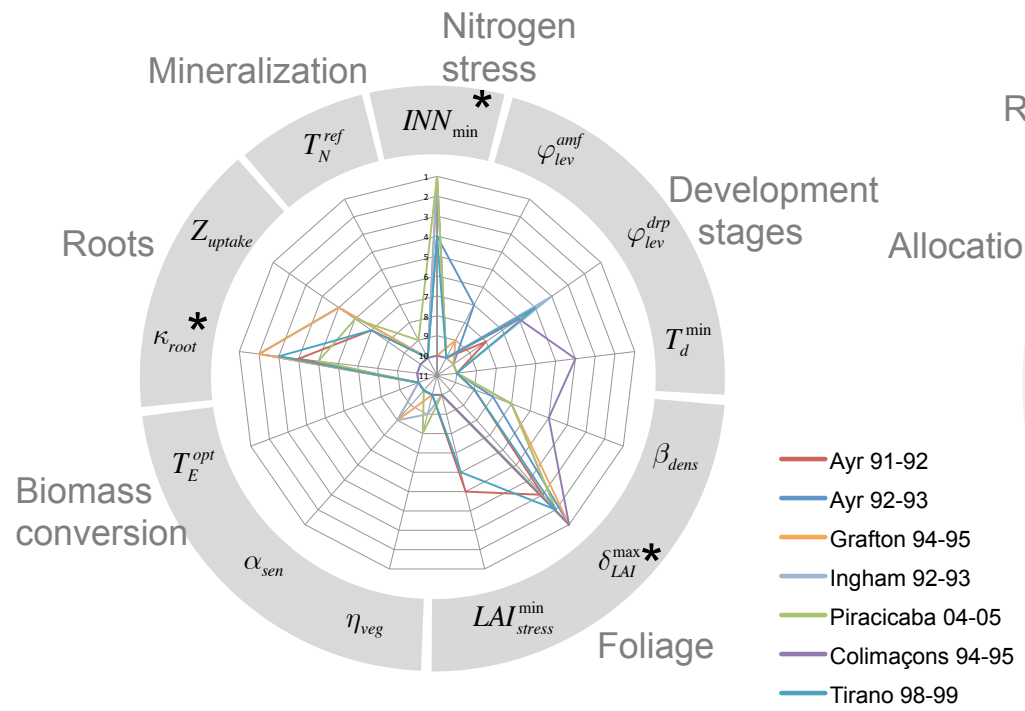

(b) ORCHIDEE parameters

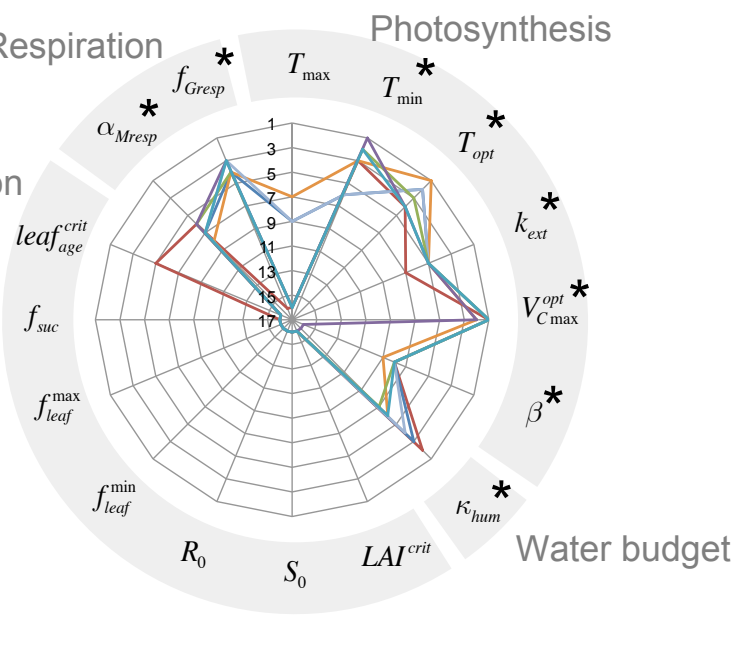

Figure 5. Parameters rankings derived from the Morris screening analysis for STICS parameters (a) and ORCHIDEE parameters (b) for seven sites (color lines). Each axis of the radar plot corresponds to the rank of a parameter, the lower the rank, the more important the parameter.

identified as influential by the Morris method). The Morris top-ranked parameters of ORCHIDEE control photosynthesis and water budget equations as well as respiration processes (Fig. 4). Three of those (the minimum and optimal temperatures for photosynthesis, $T_{\min }, T_{\mathrm{opt}}$, the maximum rate of carboxylation $V_{\mathrm{Cmax}}^{\mathrm{opt}}$ ) directly affect the rate of carboxylation $V_{\mathrm{c}}$ that is calculated from the maximum rate of carboxylation weighted by a mean leaf efficiency and scaled by a limiting factor depending on the optimum and minimum temperatures for photosynthesis. The stomatal conductance $g_{\mathrm{s}}$ that links assimilation and transpiration is defined by the Ball-Berry equation (Ball et al., 1987) as a function of assimilation and depends on the air relative humidity and $\mathrm{CO}_{2}$ concentration, scaled by a slope factor, called the BallBerry slope $(\beta)$. The root profile constant $\left(\kappa_{\text {hum }}\right)$ describes the exponential distribution of root density in the soil and is involved in the definition of available water and root temperature. Finally, the extinction coefficient $\left(k_{\text {ext }}\right)$ intervenes in an equation derived by Monsi and Saeki (1953), similar to Beer's law, which describes the attenuation of light with depth in the canopy.

Two ORCHIDEE parameters controlling autotrophic respiration also stand out, with the maintenance respiration coefficient $\left(\alpha_{\text {Mresp }}\right)$ and the fraction of biomass allocated to growth respiration $\left(f_{\text {Gresp }}\right)$. The leaf age parameter that is involved in the biomass allocation also ranked high (fifth most important) but only for one site and is therefore not retained for the rest of the study.
For the chained model ORCHIDEE-STICS, the 11 most influential parameters show a good agreement between sites for the most important parameters as seen in Fig. 5 where ranking lines overlap for most of the parameters. Building on the results of the Morris screening analysis, we select the eight top-ranked parameters for ORCHIDEE and three for STICS that were revealed as influential for biomass for further uncertainty and sensitivity analysis.

\subsection{Uncertainty analysis: parameters controlling biomass uncertainty at a typical site}

In this section, we attribute the harvested biomass uncertainty to the uncertainty of the ORCHIDEE vs. STICS parameters. The simulated biomass uncertainty is a function of time during the growing season, and it differs between sites. In Fig. 6, we show the contributions of ORCHIDEE and STICS parameters, respectively, to the total uncertainty for one typical site, Grafton, Australia, during the 1994-1995 growing season, which has climate conditions within the range of other sites. Figure $6 \mathrm{a}-\mathrm{c}$ display the normalized frequency distributions of simulated biomass obtained from ensemble runs for three times in the growing season: (1) very early in the cycle in Fig. 6a, at 100 days after planting (DAP), (2) during the peak growing season in Fig. 6b, at 200 DAP and (3) shortly before harvest in Fig. 6c, at 350 DAP. We distinguish between the normalized frequency distributions of simulated biomass when considering the uncertainty propagated from STICS parameters alone (green), ORCHIDEE parameters alone (yellow), and from ORCHIDEE and STICS parameters together (brown), along with their best-fit normal 
(a)

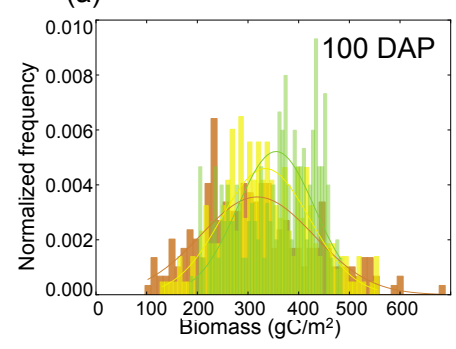

(d)

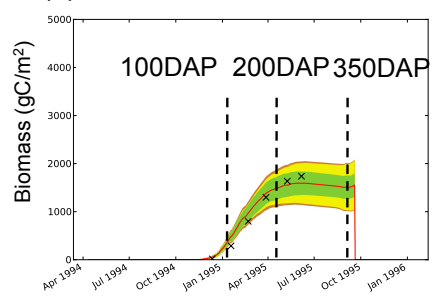

(b)

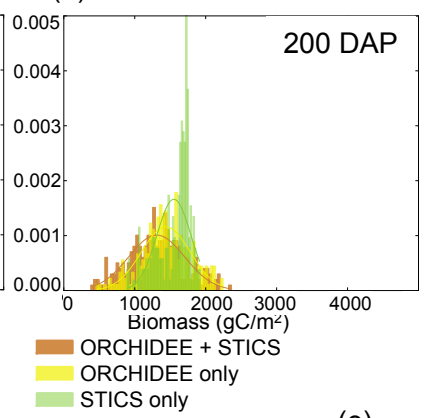

(e) (c)
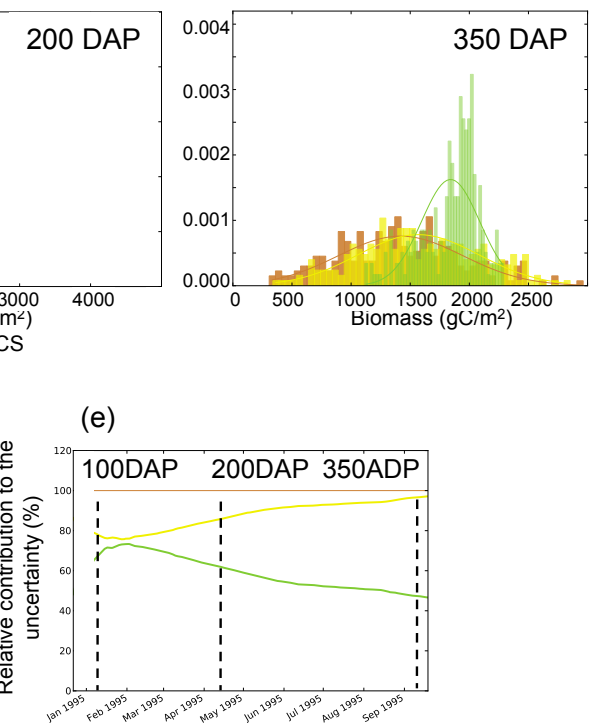

Figure 6. Uncertainty analysis for the site Grafton 94-95. (a-c) Probability distributions of harvested biomass simulated after parameter uncertainty (from STICS: green, from ORCHIDEE: yellow, from ORCHIDEE+STICS: brown) has been propagated into the model. (d) Reference simulation of harvested biomass (red) and uncertainty from ORCHIDEE, STICS, ORCHIDEE+STICS. (e) Contribution (\%) of ORCHIDEE (yellow) and STICS (green) to the total uncertainty (brown) over the length of the growing season.

distributions overlaid. These distributions were obtained by Monte Carlo LHS ensemble runs (Sect. 2.4) with a sampling of parameters of STICS alone, ORCHIDEE alone and of both models together. We consider uncertainties starting from the time when biomass reaches $50 \mathrm{gC} \mathrm{m}^{-2}$ in order to discard the emergence phase during which biomass is very low and uncertainties are therefore not significant.

At 100 DAP (Fig. 6a), the uncertainty distribution of biomass related to ORCHIDEE parameters $\mathrm{U}(\mathrm{O})$ spans a slightly larger range than the distribution related to STICS, $\mathrm{U}(\mathrm{S})$, and it has more extreme values. The $\mathrm{U}(\mathrm{O})$ distribution is symmetrical around the mean value, with a standard deviation of $86.9 \mathrm{gC} \mathrm{m}^{-2}$. The $\mathrm{U}(\mathrm{S})$ distribution is non-symmetric, skewed towards larger values of biomass, and it has a slightly smaller standard deviation $\left(76.5 \mathrm{gC} \mathrm{m}^{-2}\right)$ than that of $\mathrm{U}(\mathrm{O})$. Combining $\mathrm{U}(\mathrm{O})$ and $\mathrm{U}(\mathrm{S})$ in Monte Carlo runs by varying the parameters of both models at the same time gives the total uncertainty distribution, $\mathrm{U}(\mathrm{O}+\mathrm{S})$, shown in brown in Fig. 6. This distribution has more extreme values and a higher standard deviation $\left(112.0 \mathrm{gC} \mathrm{m}^{-2}\right)$, in other words, $\mathrm{U}(\mathrm{O}+\mathrm{S})>\mathrm{U}(\mathrm{O})+\mathrm{U}(\mathrm{S})$.

At 200 DAP (Fig. 6b), and later at 350 DAP (Fig. 6c), the picture has changed. First, all uncertainty distributions are wider than at 100 DAP. Secondly, the means of $U(O)$ and $U(S)$ are no longer in agreement, with the asymmetric $\mathrm{U}(\mathrm{S})$ distribution being even more shifted towards high values of the harvested biomass. The reason for this shift is that among the variables transmitted from STICS to ORCHIDEE in the chain of models, the only one that can act to increase the biomass calculated by ORCHIDEE in the later phase of the growing season, near 350 DAP, is LAI. This is because a higher LAI will result in increased photosynthesis and therefore biomass in ORCHIDEE. However, past a certain threshold, the LAI impact saturates when the foliage is sufficient for all incoming light to be captured, and therefore, uncertainty on the STICS parameters that impact LAI will not increase the uncertainty of biomass any longer. Unlike LAI, the nitrogen stress and root profile variables controlled by the parameters of STICS continue to act as limiting factors on biomass throughout the peak and late growing season. The saturation of the biomass uncertainty associated with STICS parameters is stronger at 200 DAP than at 300 DAP, when biomass increase has slowed down and the role of LAI for driving biomass is less important.

In Fig. 6d, the total uncertainty $\mathrm{U}(\mathrm{O}+\mathrm{S})$ is given for the reference simulation (with parameters at their maximum likelihood values, red line) and the uncertainty on harvested biomass can be defined as a percentage of the harvested biomass in the reference simulation. For the Grafton site, at harvest, the overall uncertainty is $26 \%$. The relative contributions of ORCHIDEE and STICS to the total uncertainty, $\alpha_{\mathrm{O}}$ and $\alpha_{\mathrm{S}}$, respectively, are defined by $\alpha_{\mathrm{O}}=\frac{\mathrm{U}(\mathrm{O})}{\mathrm{U}(\mathrm{O}+\mathrm{S})}, \alpha_{\mathrm{S}}=$ $\frac{\mathrm{U}(\mathrm{S})}{\mathrm{U}(\mathrm{O}+\mathrm{S})}$. The evolution of these contributions to the total uncertainty is shown in Fig. 6e. We can see in this example that $\mathrm{U}(\mathrm{O})>\mathrm{U}(\mathrm{S})$ during the entire growing season, but with a decrease of $U(S)$, and an increase of $U(O)$ such that the increase in biomass uncertainty seen in Fig. $6 \mathrm{~d}$ becomes increasingly dominated by uncertain ORCHIDEE parameters. The progressive increase in the weight of ORCHIDEE parameters 
Table 3. Uncertainty associated with STICS, ORCHIDEE, or ORCHIDEE+STICS parameters uncertainties expressed as percentage of the reference harvested biomass for each site and for each of the two uncertainty analysis.

\begin{tabular}{|c|c|c|c|c|}
\hline & & $\begin{array}{r}\text { Total uncertainty } \\
\text { (\% of observed value) }\end{array}$ & $\begin{array}{l}\text { ORCHIDEE uncertainty } \\
\text { (\% of observed value) }\end{array}$ & $\begin{array}{r}\text { STICS uncertainty } \\
\text { (\% of observed value) }\end{array}$ \\
\hline \multirow{7}{*}{$\begin{array}{l}\text { Expert-based } \\
\text { parameters' uncertainties }\end{array}$} & Ayr 1991-1992 & 35.11 & 20.43 & 20.73 \\
\hline & Ayr 1992-1993 & 27.21 & 25.26 & 9.31 \\
\hline & Ingham 1992-1993 & 38.60 & 31.42 & 21.04 \\
\hline & Grafton 1994-1995 & 26.05 & 23.92 & 14.07 \\
\hline & Piracicaba 2004-2005 & 25.49 & 23.36 & 14.00 \\
\hline & Colimaçons 1994-1995 & 41.21 & 41.87 & 18.61 \\
\hline & Tirano 1998-1999 & 44.26 & 36.80 & 30.61 \\
\hline \multirow{7}{*}{$\begin{array}{l}\text { Optimization-based } \\
\text { parameters' uncertainties }\end{array}$} & Ayr 1991-1992 & 31.20 & 14.01 & 25.64 \\
\hline & Ayr 1992-1993 & 15.84 & 15.60 & 4.58 \\
\hline & Ingham 1992-1993 & 21.66 & 22.35 & 9.19 \\
\hline & Grafton 1994-1995 & 16.84 & 15.25 & 9.81 \\
\hline & Piracicaba 2004-2005 & 14.67 & 14.80 & 5.84 \\
\hline & Colimaçons 1994-1995 & 21.31 & 20.01 & 10.28 \\
\hline & Tirano 1998-1999 & 22.26 & 18.06 & 15.03 \\
\hline
\end{tabular}

uncertainties is due to the reduction in the role played by LAI for biomass increase along the growing season. Indeed, if early in the season the foliage is crucial to allow photosynthesis and carbon allocation, later in the cycle, other processes become important as well; past a certain LAI for which all incoming light is captured, it might not even play a role anymore, and then the STICS parameters only impact biomass accumulation through nitrogen stress index and root depth.

\subsection{Uncertainty analysis: role of ORCHIDEE vs. STICS parameters in controlling biomass uncertainty at seven sites}

Table 3 summarizes the results of the overall parametric uncertainty analysis at the seven sites, including Grafton. The total uncertainty $\mathrm{U}(\mathrm{O}+\mathrm{S})$ ranges between $25.5 \%$ of biomass at Piracicaba, Brazil during 2004-2005 and 44.26\% of harvested biomass at Tirano, La Réunion in 1998-1999. This yields an average uncertainty on biomass at harvest (due to uncertain parameter values of the chained model ORCHIDEE-STICS) of $34.0 \%$ of harvested biomass across the seven sites, in the order of previous results on different variables in similar studies using process-based models, such as Dufrêne et al. (2005) who found an uncertainty of $30 \%$ on modeled NEE for forest sites in France with the CASTANEA model.

As for the ORCHIDEE vs. STICS relative contributions to the uncertainty of simulated biomass at all sites, the results at each site are not identical but display a similar general pattern shown by Fig. 7. For all sites, the ORCHIDEE parameters contribution to total uncertainty increases during the cycle, or remains approximately constant for Ingham in 1992-1993, and increases during the growing cycle to dominate entirely the total uncertainty at the end of the cycle compared to STICS parameters. The STICS contribution to overall uncertainty decreases during the growing season to reach a minimum by the end of the growing season. For sites Piracicaba during 2004-2005, Tirano in 1998-1999 and Colimaçons during 1994-1995, during the beginning of the cycle the $\mathrm{U}(\mathrm{S})$ is even larger than $\mathrm{U}(\mathrm{O})$. The results for Ayr in 1991-1992 display a less clear pattern. Indeed, at the end of the cycle, the contributions of ORCHIDEE and STICS to the total uncertainty are almost equal, due to an increase in STICS contribution during the second half of the cycle. This result confirms a hypothesis made in Valade et al. (2013) where the difficult calibration of LAI at this site was attributed to the simulation by STICS of an important stress. Indeed if a large stress is simulated by the phenological module, this can impede ORCHIDEE processes of biomass growth and therefore increases the weight of STICS parameters with respect to ORCHIDEE ones.

\subsection{Uncertainty analysis: constraining uncertainty from site optimization}

Optimizing the 11 ORCHIDEE-STICS parameters selected from the screening analysis at seven sites leads to a reduction of the width of the a priori uncertainty distribution of the parameters (Table 2). Carrying out the same uncertainty analysis with a narrower uncertainty range of parameters (thanks to their site calibration) leads to an important reduction of uncertainties of biomass, both for the STICS and ORCHIDEE components of uncertainty. This can be seen by comparing Fig. 6 (initial range of parameters) with Fig. 8 (narrower range after parameter calibration at the sites). For site Grafton during 1994-1995 for example, $\mathrm{U}(\mathrm{O}+\mathrm{S})$ gets reduced from $26 \%$ to $17 \%$ for the reference harvested biomass, $\mathrm{U}(\mathrm{O})$ from $24 \%$ to $15 \%$ and $\mathrm{U}(\mathrm{S})$ from 

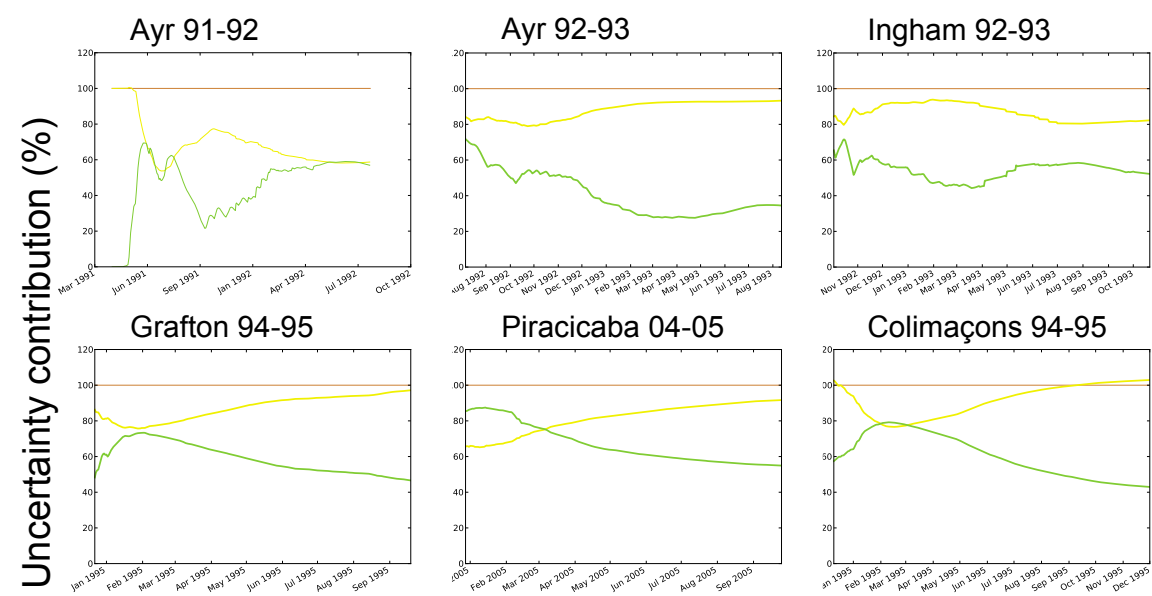

Colimaçons $94-95$

Tirano 98-99
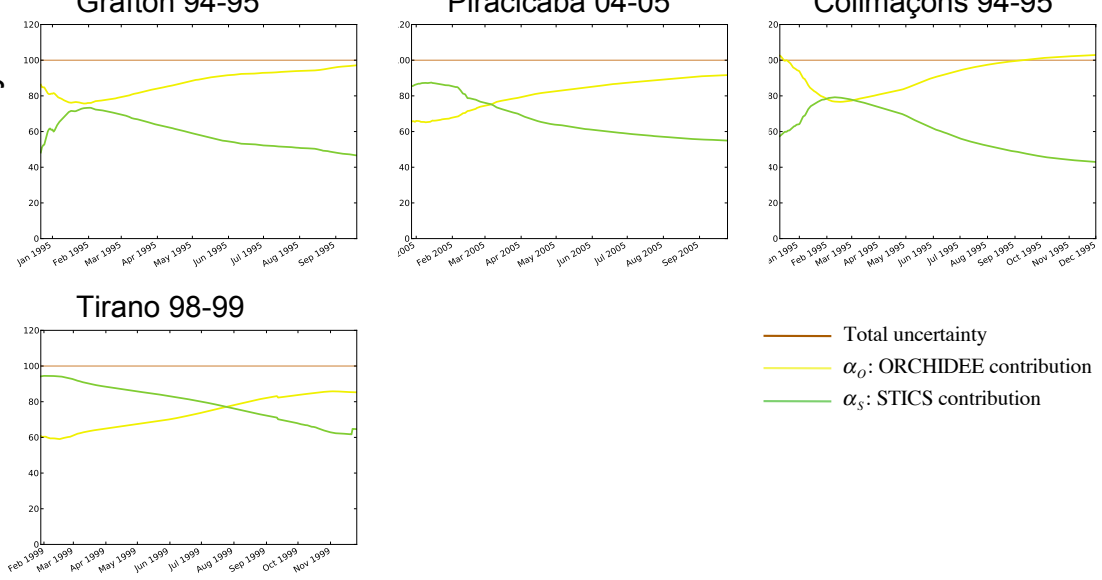

Figure 7. Contribution (\%) of ORCHIDEE (yellow) and STICS (green) to the total uncertainty (brown) over the length of the growing season for seven sites.

$14 \%$ to $10 \%$. Figure 9 and Table 3 (bottom section) show the uncertainty contributions and overall uncertainty estimates for the seven sites after observation-based reduction of the a priori uncertainty on parameters. The overall parametric uncertainty of biomass defined as the 1-sigma standard deviation of the $(\mathrm{O}+\mathrm{S})$ distribution has thus been reduced to $21 \%$ on average, to $11.48 \%$ when attributed to STICS alone, and to $17.15 \%$ when attributed to ORCHIDEE alone (Table 3).

The ORCHIDEE and STICS contributions to the total uncertainty keep the same general pattern as with the initial parameter uncertainty distribution, with a domination of ORCHIDEE parameters in the uncertainty towards the end of the growing season (Fig. 9). Compared with the first uncertainty budget with expert-based parameters uncertainties (Fig. 8), there is generally a slight decrease in the STICS contribution at the end of the season.

We have thus established full uncertainty budgets for the two components of the ORCHIDEE-STICS chain of models, which has revealed variations in the uncertainty in the biomass simulation from site to site. The next step is to discriminate between the different parameters the ones that contribute most to the overall uncertainty through a sensitivity analysis at regional scale.

\subsection{Spatial sensitivity analysis: sensitivity of sugarcane yields to the model parameters for Brazil and Australia}

The overall parametric uncertainties have been quantified at seven sites and attributed to either STICS or ORCHIDEE. The sensitivity analysis (SA) in this section will go a step further and leads to discriminate the different parameters that contribute to the spatial distribution of uncertainty over the two regions considered. This sensitivity analysis is performed at regional scale because from the previous section, we have seen that the uncertainty in the biomass simulation varies from site to site.

Ensemble runs at regional scale were conducted over Brazil and Australia, each with different value combinations for the 11 parameters previously selected through the Morris screening analysis (Table 1). The Partial Rank Correlation Coefficients (PRCC) were then calculated for each pixel in each of the two regions (see Sect. 2.5), and the SA results are discussed for two dates during the growing season, 200 and 350 days after planting (DAP). The SA results express the strength of the relationship between an uncertain parameter and the simulated biomass at harvest at each pixel. The statistical significance of the PRCC calculated for each grid cell is tested with the associated $p$ values, and non-significant PRCC are removed ( $p$ value $<0.05$ ). The first date, 100 DAP, examined for site-scale UA studies (Sect. 2.3) is not shown here, because no statistical significance was found in the correlations between the parameters and the harvested biomass 
(a)

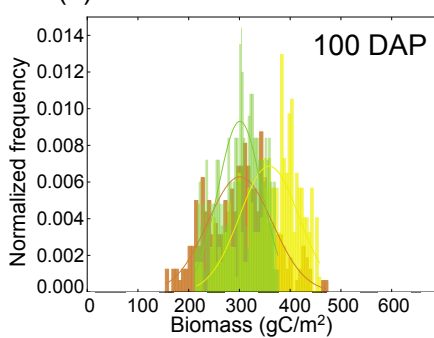

(d)

(b)

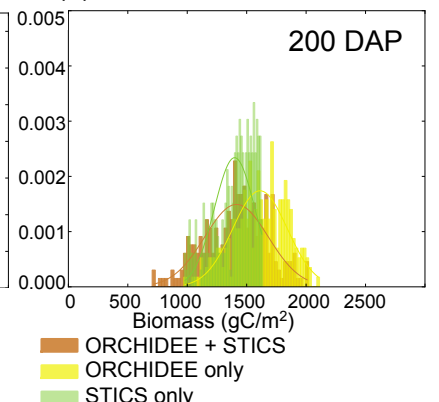

(c)

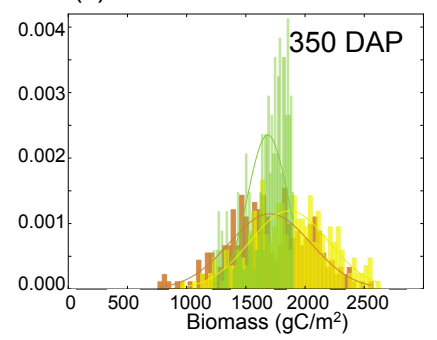

(e)
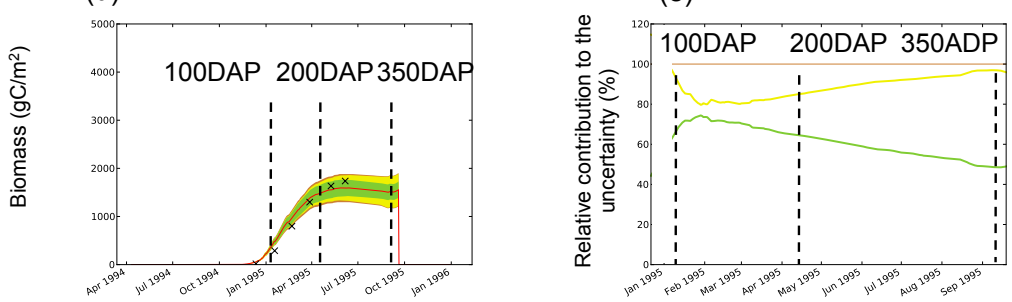

Figure 8. Uncertainty analysis for the site Grafton 94-95 after parameter uncertainty ranges have been constrained through optimization at seven sites. (a-c) Probability distributions of harvested biomass simulated after parameter uncertainty (from STICS: green, from ORCHIDEE: yellow, from ORCHIDEE+STICS: brown) has been propagated into the model. (d) Reference simulation of harvested biomass (red) and uncertainty from ORCHIDEE, STICS, ORCHIDEE+STICS. (e) Contribution (\%) of ORCHIDEE (yellow) and STICS (green) to the total uncertainty (brown) over the length of the growing season.
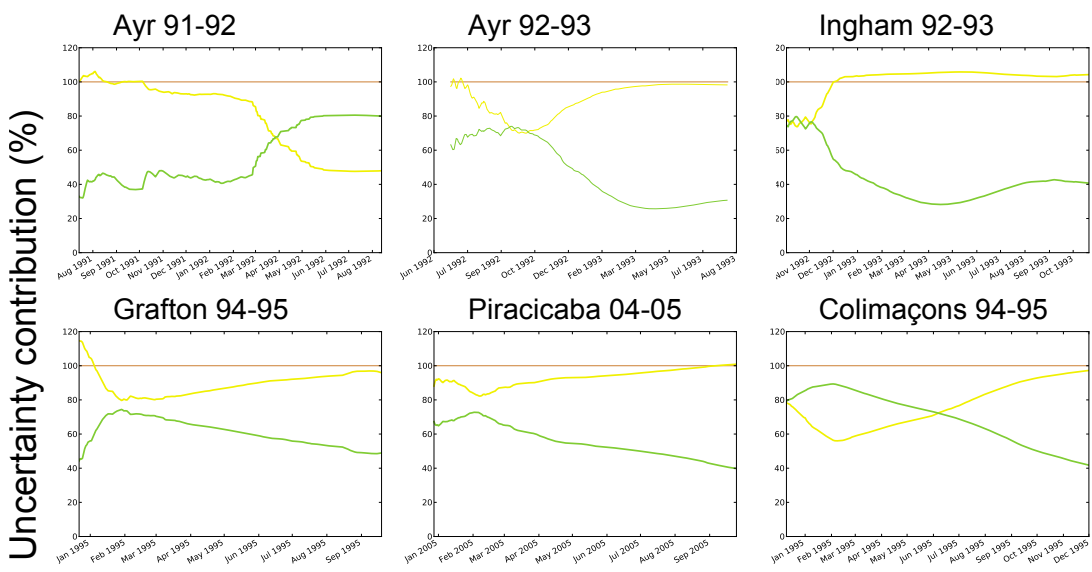

Colimaçons 94-95

Tirano 98-99
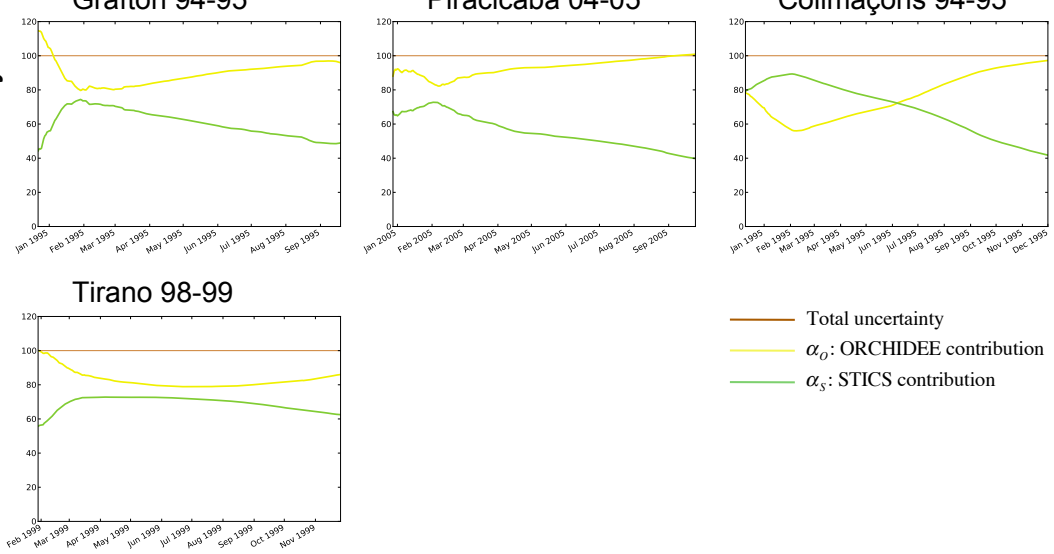

Total uncertainty

$\alpha_{o}$ : ORCHIDEE contribution

$\alpha_{s}$ : STICS contribution

Figure 9. Contribution (\%) of ORCHIDEE (yellow) and STICS (green) to the total uncertainty (brown) over the length of the growing season for seven sites after parameter uncertainty ranges have been constrained through optimization at seven sites.

at 100 DAP. Then, the pixels' statistically significant PRCC, calculated for each parameter, can be analyzed both in a geographical projection (latitude, longitude) (Figs. 11 and 12, columns 1-2 and 4-5) and in a (temperature, precipitation) climatic space projection (Figs. 11 and 12, columns 3 and 6). The regional sensitivity analysis thus carried out for sugarcane-growing areas in Brazil and Australia shows the magnitude, spatial distribution and climatic dependency of 
(a) 200DAP
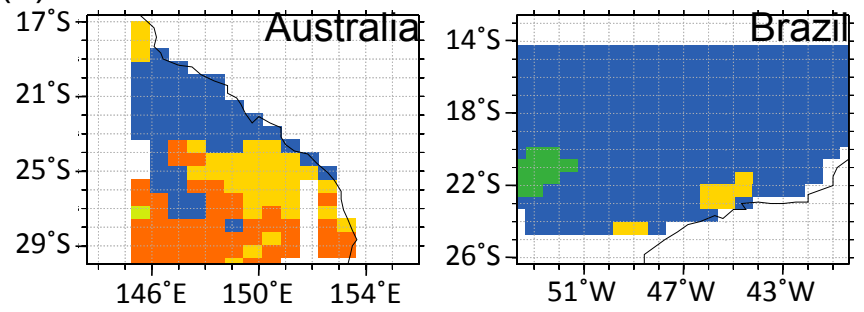

(b) 350DAP
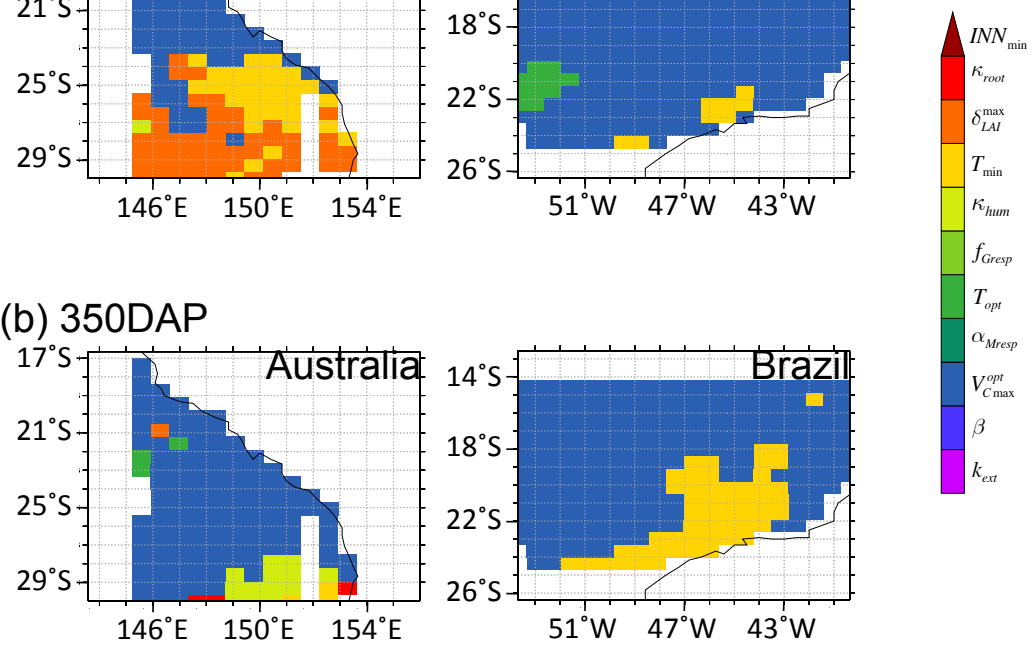

Figure 10. Spatial distribution of the most influential parameters for the simulation of harvestable biomass for two milestones during the growing season, 200 days after planting (DAP) and 350 DAP.

the sensitivity of harvested biomass to the 11 parameters previously selected through the Morris screening analysis (Table 2).

Across both regions in Brazil and Australia, we find that the sensitivity of biomass to the model parameters is not uniformly distributed. This means that the simulated yield depends on different parameters within different parts of the same region. This result shows that applying a model at one site to determine the most important parameters, and generalizing its conclusion across a region generates biased conclusions. Considering only the first most important parameter in each pixel (Fig. 10), we can see that early in the cycle (200 DAP, Fig. 10a) four parameters dominate the spatial distribution of the $\mathrm{U}(\mathrm{O}+\mathrm{S})$ uncertainty of biomass at 200 DAP, both over Brazil and Australia. These parameters are three ORCHIDEE parameters involved in the photosynthesis process, the minimum and optimum temperature for photosynthesis $T_{\min }, T_{\mathrm{opt}}$, and the maximum rate of carboxylation $V_{\mathrm{Cmax}}^{\mathrm{opt}}$, and one parameter from STICS $\delta_{\mathrm{LAI}}^{\max }$, defining the maximum rate of increase of LAI and only appearing in the Australian region. In Brazil, the parameter $V_{\mathrm{Cmax}}^{\mathrm{opt}}$ is the most important parameter for $93 \%$ of the area, whereas the optimum and minimum photosynthesis temperatures parameters only dominate in 3 and $4 \%$ of the area, respectively. In Australia, the parameters' domination is more balanced, with $37.5 \%$ for each of $V_{\mathrm{Cmax}}^{\mathrm{opt}}$ and $\delta_{\mathrm{LAI}}^{\max }$, and $25 \%$ for $T_{\min }$.

Later in the growing season (350 DAP, Fig. 10b), consistently with the results of the site-scale uncertainty analysis, the influence of the STICS parameters decreases until STICS parameters no longer appear as a dominant parameter in any of the regions. At this later stage in the season, two parameters stand out as explaining most of the uncertainty in most pixels of both regions, $V_{\mathrm{Cmax}}^{\mathrm{opt}}$ and $T_{\min }$. In Brazil, $V_{\mathrm{Cmax}}^{\mathrm{opt}}$ is still the most sensitive parameter for most of the region, but $T_{\text {opt }}$ disappeared and the area dominated by $T_{\min }$ expanded and now covers the cooler area of the southeast coastal zone, which is likely to result from the growing calendar of sugarcane in Brazil since the later part of the growing season takes place during winter in this region. In Australia, the area dominated by $V_{\mathrm{Cmax}}^{\mathrm{opt}}$ expanded into most of the region and now covers $83 \%$ of the area. In the coolest pixels, the soil-related parameters appear with the two root profile parameters from STICS and from ORCHIDEE $\kappa_{\text {root }}$ and $\kappa_{\text {hum }}$.

Figures 11 and 12 focus on the values of the PRCC for each parameter, as well as their spatial distribution. Their projection in a temperature-precipitation space for a given time (Fig. 11 for 200 DAP; Fig. 12 for 350 DAP) give more insight on the dependency of the sensitivity to the climatic conditions along the growing cycle. As an example, the sensitivity of the simulated biomass to $T_{\min }$ is highly sensitive to the average temperature of the location. At low-temperature sites, where temperature is a limiting factor for crop growth (below $17^{\circ} \mathrm{C}$ ), the $\mathrm{PRCC}$ is higher than 0.8 , whereas at hightemperature sites (above $22^{\circ} \mathrm{C}$ ) the PRCC is below 0.3 . Sites with temperatures above $25^{\circ} \mathrm{C}$ do not even show significant correlations (grey symbols on the scatter plot).

For the parameter $\kappa_{\text {hum }}$, which describes the root profile of the cane (inverse of root depth), the dependency is most obvious on precipitation amount. For annual precipitations above $2500 \mathrm{~mm}$, no significant correlation is found. 

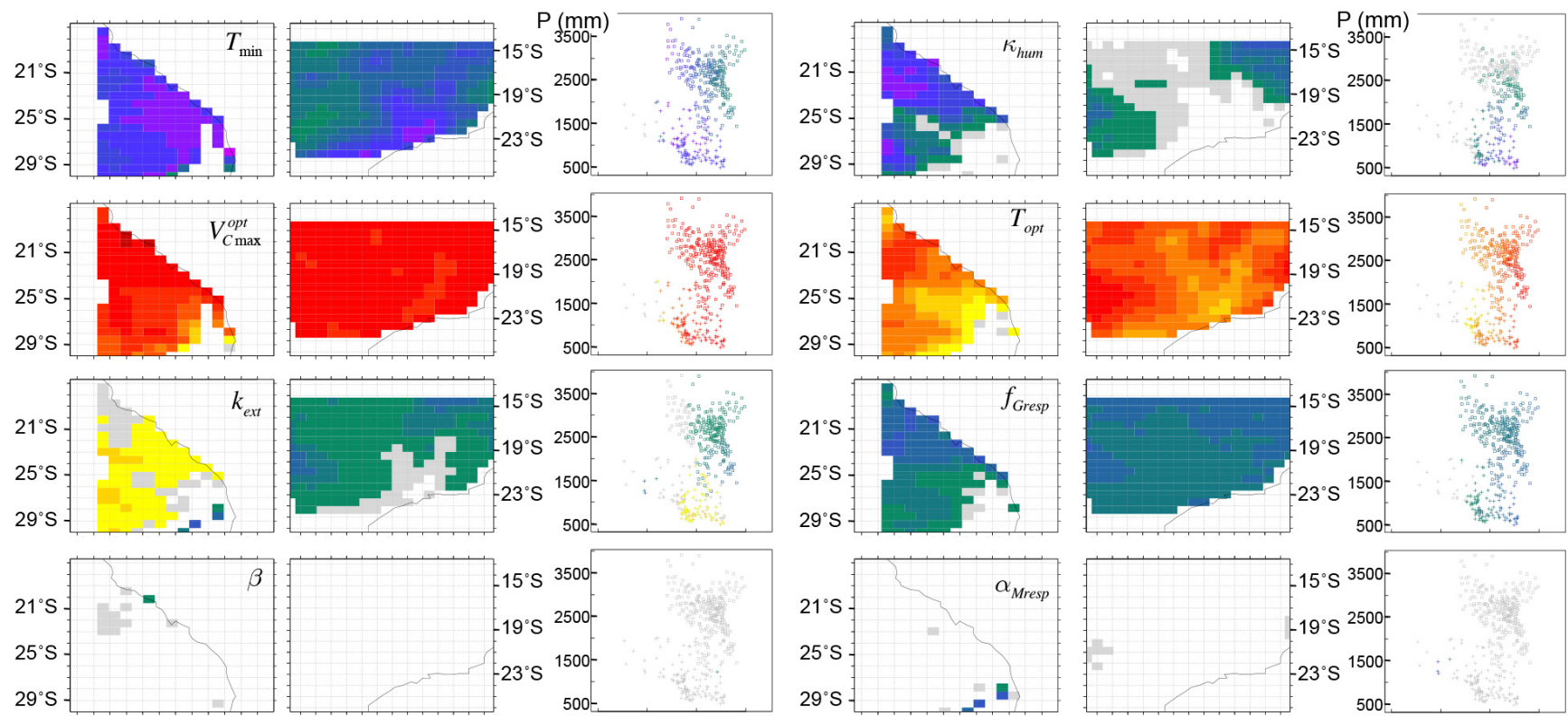

$500-$
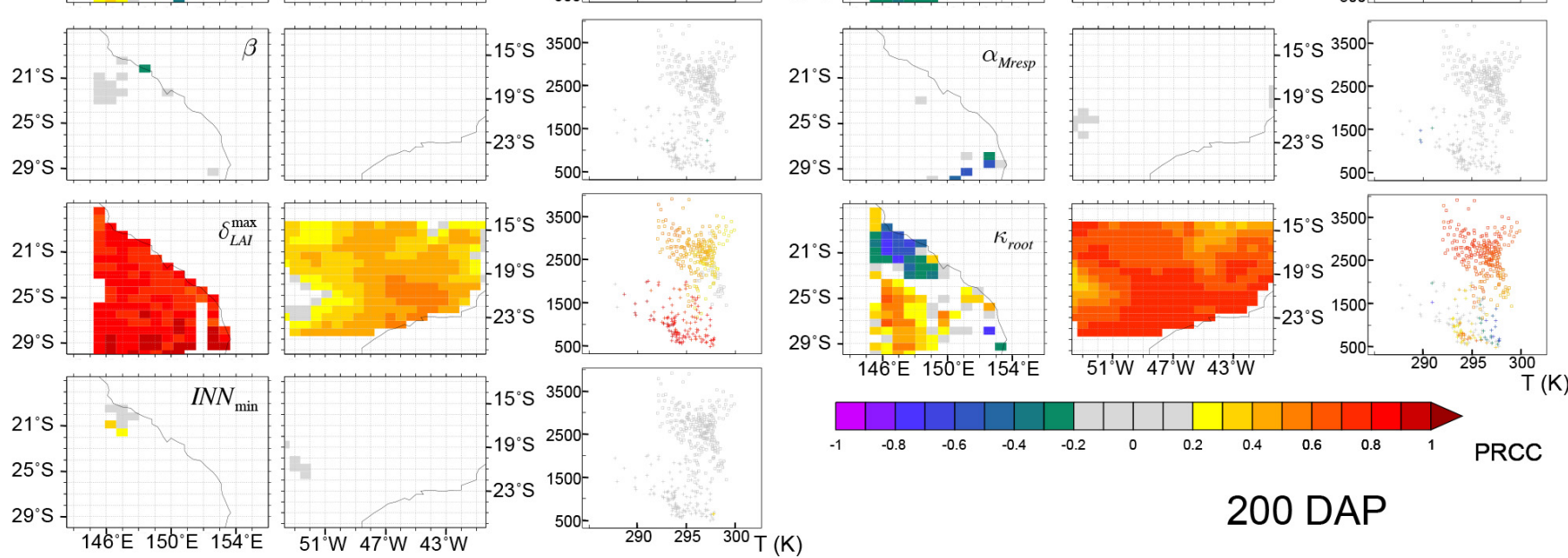

200 DAP

Figure 11. Sensitivity of ORCHIDEE-STICS to its main parameters at 200 days after planting, as measured with partial ranked correlation coefficients (PRCC). The color indicates the strength of the relation between the parameter and the harvestable biomass, which is represented spatially (columns 1, 2, 4, 5) and in a (temperature, precipitation) referential (columns 3,6).

Comparing the regional sensitivities at two times in the growing season shows again the decrease in the importance of STICS parameters, whereas all of the most important ORCHIDEE parameters have larger RPCC than earlier in the season.

\section{Concluding remarks}

In the perspective of applying spatially explicit mechanistic vegetation models such as ORCHIDEE-STICS to biofuel yield simulations, we have sought the quantification and understanding of parametric uncertainty propagation in the model, both at site level and at sub-continental scale over two large regions, Australia and Brazil. For this, a rigorous analysis of the uncertainty budget of simulated sugarcane biomass has been established, using a step-by-step tracking of uncertainty in the model.
The main parameters from the two chain components of the model responsible for most of the uncertainty propagation have been identified through a Morris screening analysis. For the ORCHIDEE carbon, water and energy model, the most influential parameters are those involved in photosynthesis equations, $T_{\min }, T_{\mathrm{opt}}, V_{\mathrm{Cmax}}^{\mathrm{opt}}$, the radiation interception parameter $k_{\text {ext }}$, the root profile constant $\kappa_{\text {hum }}$, the parameters for respiration, slope of the Ball-Berry relation $\beta$, maintenance and growth respiration parameters $f_{\text {Gresp }}$ and $\alpha_{\text {Mresp }}$. For the STICS model, the most influential parameters are those responsible for simulation of phenology, nitrogen and water stress. The parameters describing the maximum rate of carboxylation, the maximum growth rate of the root front and the threshold for nitrogen stress have been found to have the greatest role. The parameters identified are closely related to the structure of the coupling since the key variables transmitted from STICS to ORCHIDEE each convey one key parameter. 

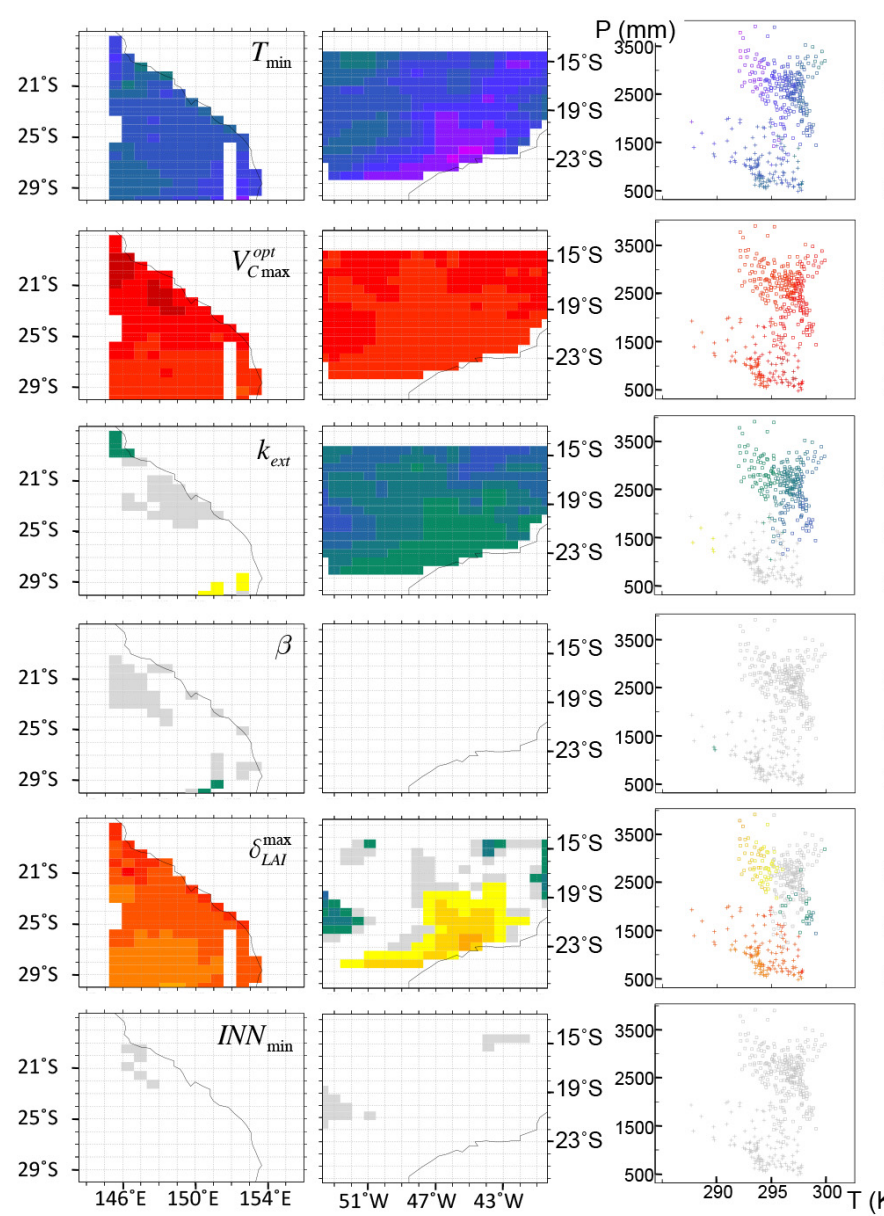
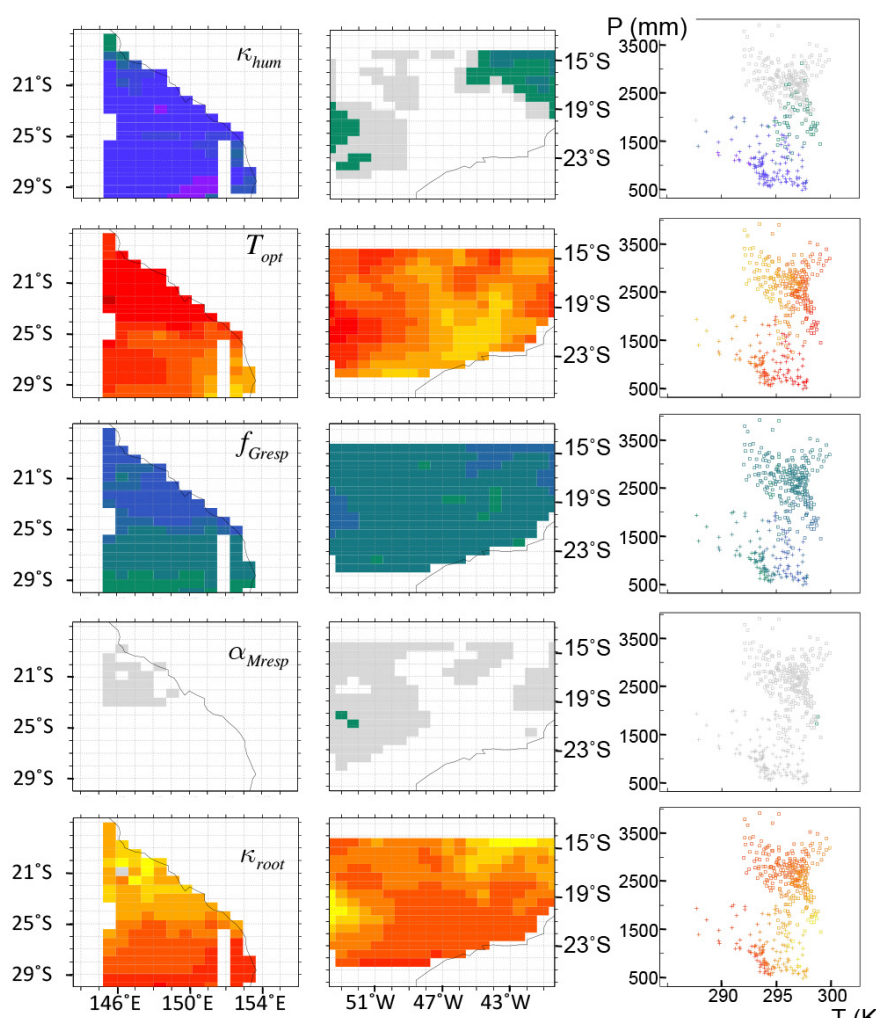

500
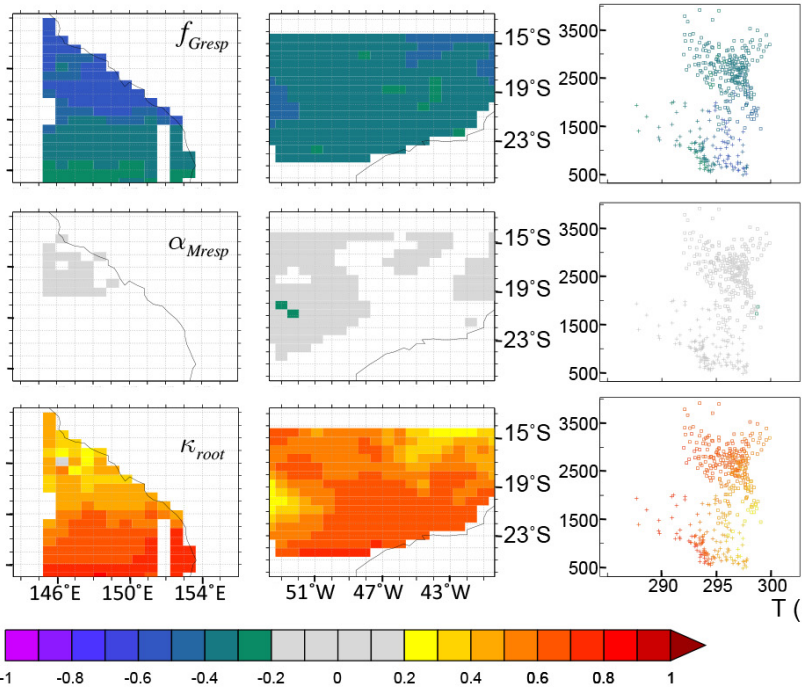

\section{DAP}

Figure 12. Sensitivity of ORCHIDEE-STICS to its main parameters at 350 days after planting, as measured with partial ranked correlation coefficients (PRCC). The color indicates the strength of the relation between the parameter and the harvestable biomass, which is represented spatially (columns 1, 2, 4, 5) and in a (temperature, precipitation) referential (columns 3,6).

We used two approaches for estimating the total uncertainty propagated from the parameters into the model by assigning uncertainties on parameters with two methods: one "pessimistic", in which a priori parameter uncertainty bounds are set based on expert judgment, and one optimistic where smaller uncertainty is derived by an optimization of the model parameters at several sites, thus providing a smaller, arguably more realistic, a priori uncertainty range.

We found that all these parameters together contribute to an overall uncertainty of $21 \%$ on sugarcane biomass simulations with an agro-LSM model and that this amount is variable among sites with different climatic, edaphic and management situations. We also analyzed this uncertainty separately for each component of the model and found that whatever estimate chosen for the input parameter uncertainty, by the end of the growing season, the uncertainty propagated from the phenology module STICS decreases and the overall uncertainty is almost totally explained by the ORCHIDEE uncertainty. The lower uncertainty from STICS parameters compared to ORCHIDEE is likely related to the lower number of processes solved by STICS in its configuration with ORCHIDEE, and to some extent to the lower number of parameters propagating their uncertainties. The decrease in the weight of the STICS' parameters to the overall uncertainty is linked to the canopy closure (LAI sufficient to capture all incoming light) and would therefore probably happen at a different timing in the growing season for different crops. For example, soybean experiences a later canopy closure and would probably show a later diminution of the STICS contribution to overall uncertainty, therefore remaining relatively high by the end of the cycle.

The overall origin of uncertainty was then diagnosed in even more detail through a regional sensitivity analysis, allowing the identification of the parameter for which harvested biomass is most sensitive for each pixel within regions of Australia and Brazil. We revealed a strong heterogeneity of the results based on climatic conditions and also variability in time that confirms the results of the uncertainty analysis, by showing a decrease in the importance of the STICS parameters along the growing season. 
We believe that our results for the sugarcane crop simulated with the model ORCHIDEE-STICS are relevant to other agro-LSM with different crops. All these results prove the importance of establishing clear uncertainty budgets for highly parameterized models such as agro-LSM, especially when applying these models to answer questions related to political decisions such as biofuels burning topics.

As an example, combining our optimistic uncertainty estimation with the estimations from Lapola et al. (2009) for irrigated sugarcane (obtained with the model LPJml, very similar to ORCHIDEE-STICS), we can evaluate the range assorted with their estimation of land requirements to fulfill the demand for ethanol in Brazil. Similar to our study, they use a multi-continental approach, focusing on Brazil and India. They simulate with a single parameterization the sugarcane productivity over both considered countries, spanning a wide range of climatic conditions. They found a mean yield of $68.8 \mathrm{tha}^{-1}$ over Brazil and $73.3 \mathrm{tha}^{-1}$ over India, and conclude that to fulfill government targets, the sugarcane areas would need to expand by 2.8 million hectares in Brazil and 1 million hectares in India. Because the yield estimates derived in Lapola et al. (2009) are retrieved with a global agro-LSM parameterized for global applications and used in a range of climatic conditions (all of Brazil and India), we make the hypothesis that our uncertainty calculation is applicable to the LPJml results. We can then take into account the parametric uncertainty of the model and translate the potential mean production into a range of 54$83 \mathrm{tha}^{-1}$ for Brazil and $58-89 \mathrm{tha}^{-1}$ for India. The land requirements when including parameter uncertainty would then becomes 2.6-3.9 million hectares, for Brazil and 0.91.4 million hectares for India. To go further in the application of this result, and assuming that sugarcane expansion results in deforestation through direct or indirect land use change, we can translate the land expansion of sugarcane for biofuels into carbon emissions from deforestation. Several estimates of carbon emissions associated with conversion of tropical forest to croplands have been published and their results span a large range revealing the large uncertainties in this area (BSI, 2008; Cederberg et al., 2011; Searchinger et al., 2008). Discussing the uncertainty on this estimate is beyond the scope of this paper so we will only consider the value from Searchinger et al. (2008), of $604 \mathrm{tCO}_{2} \mathrm{eq} \mathrm{ha}^{-1}$. Using this conversion factor, the expansion of sugarcane calculated by Lapola et al. (2009) would result in $\mathrm{CO}_{2}$ eq emissions of $1.68 \mathrm{GtCO}_{2} \mathrm{eq}$, whereas including the parametric uncertainty of the model we obtain a range of 1.6 to $2.4 \mathrm{Gt} \mathrm{CO}_{2} \mathrm{eq}$ provoked by the Brazilian government's ethanol targets with our calculation of uncertainty.

With the choice of the study from Lapola et al. (2009) to apply our uncertainty estimates on, we favored the closeness of the models over the full consistency of the methodologies. If the primary goal had been to calculate estimates of uncertainty of land requirements in the specific region of Brazil, we would have constrained our parameter ranges for conditions of this region, which would have resulted in lower uncertainty ranges for area requirements. However, we want to stress that agro-LSMs like ORCHIDEE-STICS or LPJml are designed for global studies and their parameters are therefore supposed to cover the full range of climatic conditions, even when they are used for regional applications. This quick application of our uncertainty calculation proves how important it is to consider the uncertainty when addressing issues aimed at decision-makers.

\section{The Supplement related to this article is available online at doi:10.5194/gmd-7-1225-2014-supplement.}

Acknowledgements. This study was performed using HPC resources from GENCI-CCRT (Grant 2012-016328). We acknowledge Philippe Peylin for his help with Bayesian optimization and Patrick Brockmann for his help with data visualization.

Edited by: H. Sato

\section{References}

Ball, J. T., Woodrow, I. E., and Berry, J. A.: A model predicting stomatal conductance and its contribution to the control of photosynthesis under different environmental conditions, Progr. Photosyn. Res., 221-224, 1987.

Black, E., Vidale, P. L., Verhoef, A., Cuadra, S. V., Osborne, T., and Van den Hoof, C.: Cultivating $\mathrm{C} 4$ crops in a changing climate: sugarcane in Ghana, Environ. Res. Lett., 7, 044027, doi:10.1088/1748-9326/7/4/044027, 2012.

Bouman, B.: A framework to deal with uncertainty in soil and management parameters in crop yield simulation: a case study for rice, Agr. Systems, 46, 1-17, 1994.

Brisson, N., Mary, B., Ripoche, D., Jeuffroy, M.-H., Ruget, F., Nicoullaud, B., Gate, P., Devienne-Barret, F., Antonioletti, R., Durr, C., Richard, G., Beaudoin, N., Recous, S., Tayot, X., Plenet, D., Cellier, P., Machet, J.-M., Meynard, J.-M., and Delécolle, R.: STICS: a generic model for the simulation of crops and their water and nitrogen balances, I. Theory and parameterization applied to wheat and corn, Agronomie, 18, 311-346, 1998.

Brisson, N., Gary, C., Justes, E., Roche, R., Mary, B., Ripoche, D., Zimmer, D., Sierra, J., Bertuzzi, P., and Burger, P.: An overview of the crop model STICS, Euro. J. Agronom., 18, 309-332, 2003.

BSI: PAS 2050: 2008 Specification for the assessment of the life cycle greenhouse gas emissions of goods and services. British Standards Institution, 2008.

Campolongo, F., Cariboni, J., and Saltelli, A.: An effective screening design for sensitivity analysis of large models, Environ. Model. Softw., 22, 1509-1518, 2007.

Cariboni, J., Gatelli, D., Liska, R., and Saltelli, A.: The role of sensitivity analysis in ecological modelling, Ecol. Model., 203, 167182, 2007.

Cederberg, C., Persson, U. M., Neovius, K., Molander, S., and Clift, R.: Including carbon emissions from deforestation in the carbon footprint of Brazilian beef, Environ. Sci. Technol., 45, 17731779, 2011. 
Cheeroo-Nayamuth, F. C., Robertson, M. J., Wegener, M. K., and Nayamuth, A. R. H.: Using a simulation model to assess potential and attainable sugar cane yield in Mauritius, Field Crops Res., 66, 225-243, 2000.

Cuadra, S. V., Costa, M. H., Kucharik, C. J., Da Rocha, H. R., Tatsch, J. D., Inman-Bamber, G., Da Rocha, R. P., Leite, C. C., and Cabral, O. M. R.: A biophysical model of Sugarcane growth, GCB Bioenergy 4, 36-48, 2012.

Dee, D. P., Uppala, S. M., Simmons, A. J., Berrisford, P., Poli, P., Kobayashi, S., Andrae, U., Balmaseda, M. A., Balsamo, G., Bauer, P., Bechtold, P., Beljaars, A. C. M., van de Berg, L., Bidlot, J., Bormann, N., Delsol, C., Dragani, R., Fuentes, M., Geer, A. J., Haimberger, L., Healy, S. B., Hersbach, H., Hólm, E. V., Isaksen, L., Kållberg, P., Köhler, M., Matricardi, M., McNally, A. P., Monge-Sanz, B. M., Morcrette, J. J., Park, B. K., Peubey, C., de Rosnay, P., Tavolato, C., Thépaut, J. N., and Vitart, F.: The ERA-Interim reanalysis: configuration and performance of the data assimilation system, Q. J. Roy. Meteorol. Soc., 137, 553597, 2011.

Demirbas, A.: Biofuels sources, biofuel policy, biofuel economy and global biofuel projections, Energy Conversion Manage., 49, 2106-2116, 2008.

de Vries, S. C., van de Ven, G. W. J., van Ittersum, M. K., and Giller, K. E.: Resource use efficiency and environmental performance of nine major biofuel crops, processed by first-generation conversion techniques, Biomass Bioenergy, 34, 588-601, 2010.

Doornbosch, R. and Steenblik, R.: Biofuels: Is the cure worse than the disease?, Revista Virtual REDESMA 2, 63-100, 2008.

Dufrêne, E., Davi, H., François, C., Maire, G. L., Dantec, V. L., and Granier, A.: Modelling carbon and water cycles in a beech forest: Part I: Model description and uncertainty analysis on modelled NEE, Ecol. Model., 185, 407-436, 2005.

Fargione, J., Hill, J., Tilman, D., Polasky, S., and Hawthorne, P.: Land Clearing and the Biofuel Carbon Debt, Science, 319, 12351238, 2008.

Georgescu, M., Lobell, D. B., Field, C. B., and Mahalov, A.: Simulated hydroclimatic impacts of projected Brazilian sugarcane expansion, Geophys. Res. Lett., 40, 972-977, 2013.

Gervois, S., de Noblet-Ducoudre, N., Viovy, N., Ciais, P., Brisson, N., Seguin, B., and Perrier, A.: Including Croplands in a Global Biosphere Model: Methodology and Evaluation at Specific Sites, Earth Interactions 8, 1-25, 2004.

Gervois, S., Ciais, P., de Noblet-Ducoudré, N., Brisson, N., Vuichard, N., and Viovy, N.: Carbon and water balance of European croplands throughout the 20th century, Global Biogeochem. Cy., 22, GB2022, doi:10.1029/2007GB003018, 2008.

Groenendijk, M., Dolman, A. J., van der Molen, M. K., Leuning, R., Arneth, A., Delpierre, N., Gash, J. H. C., Lindroth, A., Richardson, A. D., Verbeeck, H., and Wohlfahrt, G.: Assessing parameter variability in a photosynthesis model within and between plant functional types using global Fluxnet eddy covariance data, Agr. Forest Meteorol., 151, 22-38, 2011.

Hill, J., Nelson, E., Tilman, D., Polasky, S., and Tiffany, D.: Environmental, economic, and energetic costs and benefits of biodiesel and ethanol biofuels, Proc. Natl. Aca. Sci., 103, 1120611210, 2006.

Howarth, R. W., Bringezu, S., Martinelli, L. A., Santoro, R., Messem, D., and Sala, O. E.: Introduction: Biofuels and the Environment in the 21st Century, Biofuels: environmental conse- quences and interactions with changing land use, Proceedings of the Scientific Committee on Problems of the Environment (SCOPE) International Biofuels Project Rapid Assessment, 2225, 2008.

IEA: Biofuels for transport An international perspective, International Energy Agency, 210 pp., 2004.

IEA: Technology Roadmap, Biofuels for Transport, 2011.

Keating, B. A., Robertson, M. J., Muchow, R. C., and Huth, N. I.: Modelling sugarcane production systems I. Development and performance of the sugarcane module, Field Crops Research 61, 253-271, 1999.

Krinner, G., Viovy, N., de Noblet-Ducoudré, N., Ogée, J., Polcher, J., Friedlingstein, P., Ciais, P., Sitch, S., and Prentice, I. C.: A dynamic global vegetation model for studies of the coupled atmosphere-biosphere system, Global Biogeochem. Cy., 19, GB1015, doi:10.1029/2003GB002199, 2005.

Kuppel, S., Chevallier, F., and Peylin, P.: Quantifying the model structural error in carbon cycle data assimilation systems, Geosci. Model Dev., 6, 45-55, doi:10.5194/gmd-6-45-2013, 2013.

Lapola, D. M., Priess, J. A., and Bondeau, A.: Modeling the land requirements and potential productivity of sugarcane and jatropha in Brazil and India using the LPJmL dynamic global vegetation model, Biomass Bioenergy, 33, 1087-1095, 2009.

Loarie, S. R., Lobell, D. B., Asner, G. P., Mu, Q., and Field, C. B.: Direct impacts on local climate of sugar-cane expansion in Brazil, Nature Clim. Change, 1, 105-109, 2011.

Macedo, I. C., Seabra, J. E. A., and Silva, J. E. A. R.: Greenhouse gases emissions in the production and use of ethanol from sugarcane in Brazil: The 2005/2006 averages and a prediction for 2020, Biomass Bioenergy, 32, 582-595, 2008.

Marin, F. R., Jones, J. W., Royce, F., Suguitani, C., Donzeli, J. L., Wander Filho, J. P., and Nassif, D. S.: Parameterization and evaluation of predictions of DSSAT/CANEGRO for Brazilian sugarcane, Agronomy J., 103, 304-315, 2011.

Marino, S., Hogue, I. B., Ray, C. J., Kirschner, D. E., Marino, S., Hogue, I., Ray, C., and Kirschner, D.: A methodology for performing global uncertainty and sensitivity analysis in systems biology, J. Theor. Biol., 254, 178-196, doi:10.1016/j.jtbi.2008.04.011, 2008.

McKay, M. D., Beckman, R. J., and Conover, W. J.: Comparison of Three Methods for Selecting Values of Input Variables in the Analysis of Output from a Computer Code, Technometrics, 21, 239-245, 1979.

Medlyn, B. E., Robinson, A. P., Clement, R., and McMurtrie, R. E.: On the validation of models of forest $\mathrm{CO}_{2}$ exchange using eddy covariance data: some perils and pitfalls, Tree Physiology, 25, 839-857, 2005.

Monod, H., Naud, C., and Makowski, D.: Uncertainty and sensitivity analysis for crop models, in: Working with Dynamic Crop Models, Evaluation, Analysis, Parameterization and Applications, edited by: Wallach, D., Makowski, D., and Jones, J. W., Elsevier, Amsterdam, 55-100, 2006.

Monsi, M. and Saeki, T.: Über den Lichtfaktor in den Pflanzengesellschaften und seine Bedeutung für die Stoffproduktion, Japanese J. Botany, 14, 22-52, 1953.

Morris, M. D.: Factorial sampling plans for preliminary computational experiments, Technometrics, 33, 161-174, 1991. 
Muchow, R. C., Spillman, M. F., Wood, A. W., and Thomas, M. R.: Radiation interception and biomass accumulation in a sugarcane crop grown under irrigated tropical conditions, Austr. J. Agr. Res., 45, 37-49, 1994.

Naylor, R. L., Liska, A. J., Burke, M. B., Falcon, W. P., Gaskell, J. C., Rozelle, S. D., and Cassman, K. G.: The Ripple Effect: Biofuels, Food Security, and the Environment, Environment: Science and Policy for Sustainable Development, 49, 30-43, 2007.

OECD: OECD-FAO Agricultural Outlook 2012-2021, June 2012 Edn., OECD Publishing and FAO, 2012.

Poulter, B., Hattermann, F., Hawkins, E. D., Zaehle, S., Sitch, S., Restrepo-Coupe, N., Heyder, U., and Cramer, W.: Robust dynamics of Amazon dieback to climate change with perturbed ecosystem model parameters, Global Change Biol., 16, 24762495, 2010.

Pujol, G.: Simplex-based screening designs for estimating metamodels, Reliab. Eng. Syst. Safety, 94, 1156-1160, 2009.

Pujol, G., Iooss, B., and Janon, A.: Sensitivity: sensitivity analysis, 1.7 ed, p. R package, 2013.

Robertson, M. J., Wood, A. W., and Muchow, R. C.: Growth of sugarcane under high input conditions in tropical Australia, I. Radiation use, biomass accumulation and partitioning, Field Crops Res., 48, 11-25, 1996.

Rosenzweig, C., Jones, J. W., Hatfield, J. L., Ruane, A. C., Boote, K. J., Thorburn, P., Antle, J. M., Nelson, G. C., Porter, C., Janssen, S., Asseng, S., Basso, B., Ewert, F., Wallach, D., Baigorria, G., and Winter, J. M.: The Agricultural Model Intercomparison and Improvement Project (AgMIP): Protocols and pilot studies, Agr. Forest Meteorol., 170, 166-182, 2013.

Saltelli, A. and Marivoet, J.: Non-parametric statistics in sensitivity analysis for model output: a comparison of selected techniques, Reliab. Eng. Syst. Safety, 28, 229-253, 1990.

Saltelli, A., Tarantola, S., Campolongo, F., and Ratto, M.: Sensitivity Analysis in practice. A Guide to Assessing Scientific Models, Halsted Press New York, NY, USA, 2004.

Schubert, C.: Can biofuels finally take center stage?, Nat. Biotech., 24, 777-784, 2006.
Searchinger, T., Heimlich, R., Houghton, R.A., Dong, F., Elobeid, A., Fabiosa, J., Tokgoz, S., Hayes, D., and Yu, T.-H.: Use of US Croplands for Biofuels Increases Greenhouse Gases Through Emissions from Land-Use Change, Science, 319, 1238-1240, 2008.

Sorda, G., Banse, M., and Kemfert, C.: An overview of biofuel policies across the world, Energy Policy, 38, 6977-6988, 2010.

Surendran Nair, S., Kang, S., Zhang, X., Miguez, F. E., Izaurralde, R. C., Post, W. M., Dietze, M. C., Lynd, L. R., and Wullschleger, S. D.: Bioenergy crop models: descriptions, data requirements, and future challenges, GCB Bioenergy, 4, 620-633, 2012.

Tarantola, A.: Inverse problem theory: methods for data fitting and model parameter estimation, Elsevier, Distributors for the United States and Canada, Elsevier Science Pub. Co., Amsterdam, New York, New York, NY, USA, 1987.

Valade, A., Vuichard, N., Ciais, P., Ruget, F., Viovy, N., Gabrielle, B., Huth, N., and Martiné, J. F.: ORCHIDEE-STICS, a processbased model of sugarcane biomass production: calibration of model parameters governing phenology, GCB Bioenergy, 2013.

Verbeeck, H., Samson, R., Verdonck, F., and Lemeur, R.: Parameter sensitivity and uncertainty of the forest carbon flux model FORUG: a Monte Carlo analysis, Tree Physiol., 26, 807-817, 2006.

von Blottnitz, H. and Curran, M. A.: A review of assessments conducted on bio-ethanol as a transportation fuel from a net energy, greenhouse gas, and environmental life cycle perspective, J. Cleaner Production, 15, 607-619, 2007.

Wang, X., He, X., Williams, J., Izaurralde, R., and Atwood, J.: Sensitivity and uncertainty analyses of crop yields and soil organic carbon simulated with EPIC, T. Am. Soc. Agr. Eng., 48, 10411054, 2005.

Wyss, G. D. and Jorgensen, K. H.: A user's guide to LHS: Sandia's Latin hypercube sampling software, SAND98-0210, Sandia National Laboratories, Albuquerque, NM, 1998.

Zaehle, S., Sitch, S., Smith, B., and Hatterman, F.: Effects of parameter uncertainties on the modeling of terrestrial biosphere dynamics, Global Biogeochem. Cy., 19, GB3020, doi:10.1029/2004GB002395, 2005. 